\title{
Time-varying state variable risk premia in the ICAPM *
}

\author{
Pedro Barroso ${ }^{\mathrm{a}}$, Martijn Boons ${ }^{\mathrm{b}, \mathrm{c}, *}$, Paul Karehnke ${ }^{\mathrm{d}}$ \\ ${ }^{a}$ The University of New South Wales, Sydney, NSW 2052, Australia \\ ${ }^{b}$ Nova School of Business and Economics, Rua Holanda 1, 2775-405 Carcavelos, Portugal \\ ${ }^{c}$ Department of Finance, Tilburg School of Economics and Management, 5000 LE Tilburg, the Netherlands \\ ${ }^{d}$ ESCP Business School, 79 Avenue de la République, 75011 Paris, France
}

\begin{abstract}
We find that the relation between state variables, such as the t-bill rate and term spread, and consumption growth is time-varying. In the cross-section of U.S. stocks, risk premia for exposure to state variables vary over time accordingly. When a state variable predicts consumption strongly relative to its own history, its annualized risk premium increases by 6\% (0.4 in Sharpe ratio). This effect implies that risk premia can switch signs and are increasing in the conditional variance of the state variable. These common drivers of time-varying risk premia are consistent with the Intertemporal CAPM. Benchmark factors contain the same conditional expected return effects as state variable risk premia.
\end{abstract}

JEL classification: G12

Keywords: Conditional asset pricing models, State variables, Intertemporal CAPM, Consumption predictability, Time-varying equity risk premia

\footnotetext{
${ }^{\star}$ We are grateful to Jonathan Lewellen (the referee), Daniel Buncic, Julien Cujean, Andras Fulop, Gleb Gertsman, Andrei Gonçalves, Bill Schwert (the editor), and seminar participants at the Australasian Finance \& Banking Conference, Empirical Finance Workshop in ESSEC, ESSEC Paris, Eurofidai Paris December Finance Meeting, European Economic Association Annual Congress in Lisbon, European Finance Association conference in Lisbon, Nova SBE in Lisbon, and UNSW in Sydney for helpful comments. This work was funded by National Funds through FCT Portugal.

${ }^{*}$ Corresponding author.

Email addresses: p.barroso@unsw.edu.au (Pedro Barroso), martijn.boons@novasbe.pt (Martijn Boons), pkarehnke@escp.eu (Paul Karehnke)
} 


\section{Introduction}

State variables, such as the t-bill rate and term spread, contain important information about the future state of the economy. However, this information content can change over time. A state variable whose shocks contain on average good news can, for prolonged periods, convey no news at all, or even bad news. In this paper, we analyze the conditional asset pricing implications of this low-frequency variation in state variable risk. We find that risk premia in the stock market for exposure to state variables that predict consumption growth are time-varying in a manner consistent with changes over time in this predictive relation. ${ }^{1}$ That is, when a state variable predicts consumption growth unusually strongly at a certain point in time, its risk premium is also larger than usual. Moreover, this time-variation in state variable risk premia is magnified when the conditional variance of a state variable is high. Thus, we document two common channels by which state variable risk premia vary over time, both of which are consistent with the conditional implications of an Intertemporal CAPM (ICAPM).

A growing literature analyzes whether risk premia in the stock market for exposure to state variables line up with macro-finance theory and, in particular, the ICAPM of Merton (1973). Recent unconditional evidence is mixed and inconclusive, however. ${ }^{2}$ A possible explanation for this lack of consensus is that state variable risk premia are time-varying. Among others, Campbell and Cochrane (2000), Cochrane (2005, Ch. 8), and Nagel and Singleton (2011) argue that conditional tests have more statistical power to distinguish between competing asset pricing models. Therefore, we test whether conditional risk premia are consistent with the ICAPM. Chen, Roll, and Ross (1986) and Ferson and Harvey (1991) represent early contributions in this spirit, but these authors do not use the theoretical restrictions of the ICAPM to decompose the timevariation in risk premia into its relevant economic components. ${ }^{3}$ Moreover, these authors use a small set of test portfolios. We follow recent arguments in the literature (see, e.g., Lewellen, Nagel, and Shanken, 2010; Ang, Liu, and Schwarz, 2020) and estimate risk premia in the large cross-section of individual stocks.

For a long historical sample from 1962 to 2017, we present three results that hold equally for four empirical ICAPM multi-factor models that have been studied widely in the literature. ${ }^{4}$ Our first model includes the dividend yield $(D Y)$, default spread $(D S)$, and term spread $(T S)$. Our second model substitutes the threemonth t-bill rate $(R F)$ for $T S$. Our third model includes the $T S$, price-to-earnings ratio $(P E)$, and value

\footnotetext{
${ }^{1}$ Our main measure of macroeconomic growth is per capita real non-durables and services consumption growth, but we show that our conclusions hold equally for industrial production and GDP growth.

${ }^{2}$ Among others, Maio and Santa-Clara (2012), Barbalau, Robotti, and Shanken (2015), and Boons (2016) analyze whether state variable risk premia are consistent in sign with how the state variables predict consumption-investment opportunities in the time series. Barbalau, Robotti, and Shanken (2015) derive a formal test of sign consistency. The estimated risk premia and conclusions on ICAPM consistency vary considerably across these papers, mostly driven by (i) the test assets used when estimating risk premia in the cross-section (portfolios sorted on different characteristics or individual stocks) and (ii) the proxy for the consumption-investment opportunity set (either stock market returns and volatility or macroeconomic growth).

${ }^{3}$ Fama (1991) advocates that asset pricing tests impose theoretical restrictions on risk prices to avoid spurious results.

${ }^{4}$ We show that our results are robust for alternative combinations of state variables, such as the factors of Ludvigson and $\mathrm{Ng}(2009)$.
} 
spread (VS) of Campbell and Vuolteenaho (2004). Our fourth model includes the DY, Cochrane and Piazzesi (2005) bond market factor $(C P)$, and term structure level factor $(L V L)$.

First, we find that the coefficients in a predictive regression of consumption growth on lagged state variables are time-varying. In a simple two-stage test, controlling for these time-varying coefficients substantially improves quarterly and annual consumption growth predictability relative to an unconditional model that includes the same state variables. Second, we find that these time-varying coefficients predict the risk premia for exposure to the state variables with a positive sign in the time series. We estimate risk premia using Fama and MacBeth (1973) cross-sectional regressions as well as portfolio sorts. The predictability we document is economically strong: state variable risk premia are significantly larger by about $6 \%$ annualized (or 0.4 in Sharpe ratio) whenever a state variable predicts consumption growth strongly relative to its own history. The implied time-series standard deviation of expected state variable risk premia is about $3 \%$ per year, which is close to the unconditional average risk premium among the state variables we study. We verify in a simulation study that these results are much more likely to be generated in a conditional rather than an unconditional ICAPM world. Third, we find that risk premia are increasing (in absolute magnitude) in the conditional variance of the state variables. When the conditional variance of a state variable is high, the effect of a time-varying relation between the state variable and future consumption growth is about twice as strong. Consequently, we estimate a risk premium of about $5 \%(-5 \%)$ for a state variable that predicts consumption growth positively (negatively) when variance is high versus about $1 \%(-1 \%)$ when variance is low.

To motivate our evidence theoretically, we propose a conditional sign restriction on the state variable risk premia that follows from a stochastic discount factor (SDF) that is linear in state variables containing news about future consumption growth (or systematic economic news, more generally). ${ }^{5}$ The unconditional implication from this SDF is that the time series and cross-section should be consistent. If a state variable predicts consumption growth with a positive sign in the time series, it should capture a positive risk premium in the cross-section. In this paper, we allow the SDF coefficients to be time-varying and assume these coefficients are proxied well by the time $t$ conditional relation between the state variables and consumption growth. This extension generates conditional implications that are consistent with the data, namely that (i) the time-varying relation between a state variable and consumption growth predicts the risk premium for that state variable with a positive sign and (ii) this effect strengthens in the conditional variance of the state variable.

Although our SDF is reduced form, these two conditional implications also hold in the ICAPM of Merton (1973), as discussed in Ferson and Harvey (1991). The main difference with previous empirical work on

\footnotetext{
${ }^{5}$ It is a common feature of equilibrium models with recursive preferences (such as Epstein and Zin (1989) and Weil (1989) utility) that news about future consumption growth is priced. See, for instance, Bansal and Yaron (2004), Restoy and Weil (2010), and Campbell (2018, Ch. 6).
} 
the ICAPM is that we follow the advice in Cochrane (2005, Ch. 9) and measure risk using the relation between the state variables and future consumption growth rather than the relation between state variables and a restricted investment opportunity set. In Merton's economy, the representative agent can only invest in a risk-free asset and a cross-section of risky stocks, such that the investment opportunity set is suitably summarized by the aggregate stock market return. However, as argued in Roll (1977), the aggregate stock market return can be a poor proxy for the return on aggregate wealth, which is unobservable.

The paper closest to ours is Boons (2016), which presents unconditional evidence that state variable risk premia in a large cross-section of individual stocks are consistent in sign with how the state variables predict macroeconomic growth in the time series. For instance, Boons finds a negative risk premium for exposure to innovations in $R F$, consistent with the fact that $R F$ predicts macroeconomic growth with a negative sign unconditionally from 1962 to 2011. However, as noted also in Harvey (1988), RF (and other state variables) predict consumption growth in a time-varying way. To see this, Fig. 1 presents the conditional relation between consumption growth and $R F$, estimated by OLS over a ten-year rolling window. We see that the predictive coefficient is large and negative in the 1970s and 1980s, suggesting that a shock to $R F$ is bad news. In contrast, the coefficient is close to zero (and sometimes significantly positive) from the turn of the century until 2014, suggesting that a positive shock to $R F$ was not bad news anymore. ${ }^{6}$ The ICAPM then predicts that this variation is mirrored in the risk premium investors require for exposure to shocks to $R F{ }^{7}$ Since $R F$ is a proxy for short-term expected inflation, this argument is consistent with recent work that analyzes whether the time-varying relation between inflation and the real economy has implications for stock and bond risk premia (see David and Veronesi, 2013; Campbell, Pflueger, and Viceira, 2014; Kang and Pflueger, 2015; Boons, Duarte, de Roon, and Szymanowska, 2020).

Empirically, we find that about $60 \%$ to $80 \%$ of the variation in expected state variable risk premia is subsumed by exposure to the factors of Fama and French $(1993,2015)$. Furthermore, we find that portfolios of the Fama-French factors that best mimic realized state variable risk premia are strongly predictable in the time series. The conditional relation between the state variables and consumption growth as well as the conditional variance of the state variables predict the returns of these mimicking portfolios with the same sign, magnitude, and significance as the state variable risk premia. This test provides new evidence on the "ambitious interpretation" that Fama and French (2015) advocate for their factors. In this interpretation, the factors are diversified portfolios that provide different combinations of exposures to the unknown state variables in Merton's ICAPM. If this interpretation is correct, the factors should capture not only the uncon-

\footnotetext{
${ }^{6}$ It is perhaps unsurprising that the coefficient estimate from a ten-year rolling window regression is insignificant at times and persistent. The question we ask is whether the low-frequency variation in the predictive coefficient is economically relevant. Because we find this time-variation to contribute to consumption growth predictability, we conclude that it is not spurious.

${ }^{7}$ Similarly, Boons (2016) finds that some state variables capture an unconditional risk premium around zero, such as $D Y$. We show that there is significant variation in the relation between $D Y$ and future consumption growth and that this is associated with time-variation in the $D Y$ risk premium.
} 
ditional, but also the conditional expected return effects of state variable risk. This is exactly what we find in our tests that use conditioning information and that are therefore more powerful than previous unconditional tests. $^{8}$ In fact, our conditional evidence contributes to the asset pricing literature in general, because previous work on the time-variation in expected factor returns cannot easily distinguish between the contribution of risk versus mispricing (see, e.g., Haddad, Kozak, and Santosh, 2018).

Finally, we find that a large share of the variation in the conditional variance of the state variables is common and closely associated with macro-uncertainty (measured as the variance of consumption growth conditional on the state variables). The fact that macro-uncertainty predicts state variable risk premia in the time series contributes to recent empirical work on the cross-sectional asset pricing implications of macrouncertainty. ${ }^{9}$ In sum, we show that there are important common drivers of time-variation in state variable risk premia. Our paper thus responds to Cochrane's (2011) call for research on the factor structure of expected stock returns and strengthens the case for time-varying, rational risk premia driving return predictability.

\section{Motivation}

In this section, we motivate time-variation in state variable risk premia using a conditional sign restriction that links predictability in the time series of consumption growth to risk premia in the cross-section of stock returns. Consider the conditional asset pricing model $E_{t}\left(m_{t+1} r_{t+1, i}\right)=0$, where $r_{t+1, i}=R_{t+1, i}-R_{t+1, f}$ is the excess return of asset $i ; m_{t+1}$ is a non-negative SDF implied by the absence of arbitrage opportunities; and the expectation is conditional on the investor's information set at time $t$. Although in most equilibrium models the SDF is a non-linear function of factors and the model's (preference) parameters, we follow Cochrane (2005, Ch. 9) and approximate the SDF as a linear function of factors with time-varying coefficients:

$$
m_{t+1}=1-\boldsymbol{b}_{t}^{\prime} \boldsymbol{f}_{t+1}^{*}
$$

Throughout the paper, we present vectors and matrices in bold. Without loss of generality, we normalize the SDF to have zero-mean conditional factors $\boldsymbol{f}_{t+1}^{*}=\boldsymbol{f}_{t+1}-E_{t}\left(\boldsymbol{f}_{t+1}\right)$, such that $E_{t}\left(m_{t+1}\right)=1$. As is common in the ICAPM literature, we assume that $\boldsymbol{f}_{t+1}^{*}$ contains the unexpected excess return of the market portfolio and innovations in a set of $K$ state variables, $\varepsilon_{t+1, z_{k}}=z_{t+1, k}-E_{t}\left(z_{t+1, k}\right)$ for $k=1, \ldots, K$. Thus, $\boldsymbol{f}_{t+1}^{*}=\left(r_{t+1, m}^{*}, \boldsymbol{\varepsilon}_{t+1, \boldsymbol{z}}^{\prime}\right)^{\prime}$ and $\boldsymbol{b}_{t}=\left(b_{t, m}, \boldsymbol{b}_{t, \boldsymbol{z}}^{\prime}\right)^{\prime}$.

In this paper, we test the hypothesis that $b_{t, z_{k}}>0$ when $z_{t, k}$ forecasts consumption with a positive sign, and vice versa. Given that marginal utility is lower in good states of the world, assets that pay off when $z_{t, k}$ signals high future consumption growth are risky and demand high expected returns. The prediction

\footnotetext{
${ }^{8}$ Petkova (2006), Maio and Santa-Clara (2012), Barbalau, Robotti, and Shanken (2015), and Cooper and Maio (2019) provide some evidence that the Fama-French factors are unconditionally consistent with an ICAPM interpretation, but the inference is shown to be sensitive to the chosen set of test portfolios.

${ }^{9}$ Boguth and Kuehn (2013), Bansal, Kiku, Shaliastovich, and Yaron (2014), and Campbell, Giglio, Polk, and Turley (2018) show that macro-uncertainty risk is priced unconditionally in different asset classes.
} 
that investors hedge shocks to future consumption growth is common to many equilibrium models and the ICAPM. In particular, as Merton (1973, p. 876) writes: “An 'unfavorable' shift in the opportunity set variable $x_{k}$ [state variable] is defined as a change in $x_{k}$ such that (future) consumption will fall for a given level of (future) wealth."

In our empirical analysis, we proxy the coefficients in $\boldsymbol{b}_{t}$ using the conditional relation between a state variable and future consumption growth estimated over a backward-looking rolling window. This approach allows us to test the conditional asset pricing implications from the model in Eq. (1) using only information that is known at time $t$. An alternative approach is to assume that the SDF coefficients, $\boldsymbol{b}_{t}$, vary over time as a linear function of some instruments (see Cochrane, 2005, Ch. 8). However, this approach is designed to estimate the unconditional asset pricing implications from the conditional model in Eq. (1). Another advantage of our approach is that it does not require ex ante knowledge of the instruments that guide the time-variation.

Eq. (1) implies a beta asset pricing model identical to the ICAPM of Merton (1973, Eq. 32):

$$
E_{t}\left(r_{t+1, i}\right)=\lambda_{t+1, m} \beta_{t, i, m}+\lambda_{t+1, \boldsymbol{z}}^{\prime} \boldsymbol{\beta}_{t, i, \boldsymbol{z}}
$$

where $E_{t}\left(r_{t+1, i}\right)$ is the expected excess return of asset $i$ and

$$
\boldsymbol{\lambda}_{t+1}=\left(\lambda_{t+1, m}, \boldsymbol{\lambda}_{t+1, \boldsymbol{z}}^{\prime}\right)^{\prime}=\operatorname{Var}_{t}\left(\boldsymbol{f}_{t+1}^{*}\right) \boldsymbol{b}_{t}
$$

is the $K+1$-vector of risk premia for exposure to the market $\left(\beta_{t, i, m}\right)$ and the state variables $\left(\boldsymbol{\beta}_{t, i, \boldsymbol{z}}\right)$. We analyze the conditional implications of this model by conducting cross-sectional regressions of stock returns in each period $t+1$ on lagged exposures, $\beta_{t, i, m}$ and $\boldsymbol{\beta}_{t, i, \boldsymbol{z}}$. These exposures are the time $t$ slope coefficients from the return-generating process

$$
r_{s+1, i}=\alpha_{t, i}+\beta_{t, i, m} r_{s+1, m}+\boldsymbol{\beta}_{t, i, \boldsymbol{z}}^{\prime} \boldsymbol{\varepsilon}_{s+1, \boldsymbol{z}}+\nu_{s+1, i}
$$

where the time index $s$ runs up to $t-1$ to indicate that we use only historical information. As shown in Fama (1976), the cross-sectional risk premium estimates represent the return of a zero-investment portfolio with a beta of one to the factor of interest and a beta of zero to all remaining factors in the model. These returns thus recover the risk premia $\boldsymbol{\lambda}_{t+1}$ and estimate the conditional expected excess return investors require to invest in a portfolio with a unit conditional factor beta.

There is already a long literature analyzing time-variation in the market risk premium, $\lambda_{t+1, m}$, in crosssectional tests (see, e.g., Jagannathan and Wang, 1996; Lettau and Ludvigson, 2001; Lewellen and Nagel, 2006) as well as due to the hedge component of the ICAPM (see, e.g., Scruggs, 1998; Rossi and Timmermann, 2015). Instead, our main interest is in analyzing the time-variation in the state variable risk premia, $\boldsymbol{\lambda}_{t+1, \boldsymbol{z}}$. To ascertain that our results are not driven by a time-varying market risk premium, we orthogonalize the 
innovations in the state variables from the market in our empirical analysis.

When the innovations in the state variables are also conditionally orthogonal to each other, the state variable risk premia in $\boldsymbol{\lambda}_{t+1, \boldsymbol{z}}$ are identical in sign to the respective elements of $\boldsymbol{b}_{t, \boldsymbol{z}}$ (see Eq. (3)). Empirically, the off-diagonal elements of $\operatorname{Var}_{t}\left(\boldsymbol{\epsilon}_{t+1, \boldsymbol{z}}\right)$ are typically small for the set of state variables we consider. Thus, the model implies a positive conditional risk premium, $\lambda_{t+1, z_{k}}$, whenever a state variable $k$ currently forecasts consumption growth with a positive $\operatorname{sign}\left(b_{t, z_{k}}>0\right)$. Said differently, if the predictive relation between the state variable and consumption growth varies over time, the risk premium must vary over time in a consistent manner. The model further implies that the variation in $\lambda_{t+1, z_{k}}$ due to variation in $b_{t, z_{k}}$ is magnified when the conditional variance of the state variable, $\operatorname{Var}_{t}\left(\epsilon_{t+1, z_{k}}\right)$, is high. As conditional variance increases, shocks to $z_{t, k}$ are more likely to be large in absolute magnitude. Consequently, the premium investors require for a unit beta exposure will also increase. ${ }^{10}$

Among others, Maio and Santa-Clara (2012) and Barbalau, Robotti, and Shanken (2015) test the unconditional ICAPM implication that risk aversion for a state variable is positive when the state variable forecasts returns with a positive sign. However, as argued by Roll (1977), the aggregate stock market return can be a poor proxy for the return on aggregate wealth. As returns on aggregate wealth are not directly observable, we follow the advice in Cochrane (2005, Ch. 9) and seek instead "recession state variables." Our main focus is on the predictability of consumption growth, because in the ICAPM the representative agent's consumption plan is the outcome variable that conditions on the state variables that describe the investment opportunity set. Our estimates will reveal whether (and by how much) investors' aversion to exposure to a state variable increases when that state variable predicts future consumption growth strongly relative to its own history (and when its conditional variance is high). This rationale and our empirical evidence extend to alternative measures of macroeconomic growth, such as GDP and industrial production.

Whereas Breeden (1979) shows that the ICAPM of Merton (1973) can be collapsed to the consumption CAPM under the restrictive assumption of time-separable preferences, this conclusion does not hold under more general preference structures that display time complementarity. For instance, with recursive preferences (Bergman, 1985) or habit formation (Sundaresan, 1989), an ICAPM pricing equation continues to hold and does not collapse to a consumption CAPM. Thus, our estimates will speak to what preference structure is needed to fully explain conditional state variable risk premia, $\boldsymbol{\lambda}_{t+1, \boldsymbol{z}}$.

\footnotetext{
${ }^{10}$ Although the term $\operatorname{Var}_{t}\left(\epsilon_{t+1, z_{k}}\right)$ can be divided out in Eq. (3), it is important empirically. First, it allows us to focus on the risk premium for a fixed unit beta of exposure, instead of covariance, as is common in the literature. Second, it allows for the analysis of commonalities in the variance of the state variables and macro-uncertainty, which is a key determinant of risk premia in a number of recent asset pricing models.
} 


\section{The time-varying relation between state variables and consumption growth}

In this section, we analyze whether the relation between state variables and consumption growth is timevarying in an economically important way.

\subsection{Data}

We measure consumption growth $\left(c_{t}\right)$ as the quarterly per capita growth rate in real (seasonally adjusted) consumption expenditures on nondurables and services. We consider four empirical three-factor specifications that are popular because the state variables included in each model, denoted $\boldsymbol{z}_{t}=\left(z_{t, 1}, \ldots, z_{t, K}\right)^{\prime}$, have shown strong explanatory power for the cross-section and time series. Similar to Petkova (2006), our first model contains the default spread $(D S)$ between the yield of long-term corporate BAA- and AAA-rated bonds, the dividend yield $(D Y)$ of the Center for Research in Security Prices (CRSP) value-weighted stock market index, and the term spread $(T S)$ between the yield of the ten- and one-year Treasury bond. The yield data are taken from the Federal Reserve Economic Data (FRED). In the second model, we substitute the risk-free rate for TS, as in Boons (2016). Third, we use the model of Campbell and Vuolteenaho (2004) that includes the cyclically adjusted S\&P500 price-earnings ratio $(P E)$, the small-stock value spread $(V S)$, and $T S$. Fourth, inspired by Koijen, Lustig, and Nieuwerburgh (2017), we include the bond market factor $(C P)$ of Cochrane and Piazzesi (2005), a term structure level factor $(L V L)$, and $D Y$. Thus, each model draws information from both stock and bond markets. Consistent with most empirical studies of the cross-section, our sample starts in the second quarter of 1962 and ends in the fourth quarter of 2017.

\subsection{Unconditional versus conditional consumption growth predictability}

Using these four sets of state variables, we compare the performance of unconditional versus conditional models for predicting consumption growth. First, we present in Table 1 coefficient estimates from an unconditional predictive regression of log consumption growth (cumulated over horizons $H=1,2,4$ quarters) on the state variables in a particular model:

$$
c_{t+1: t+H}=a_{\boldsymbol{z}}^{H}+\boldsymbol{b}_{\boldsymbol{z}}^{H \prime} \boldsymbol{z}_{t}+e_{t+1: t+H}^{u} .
$$

We find that some state variables predict consumption growth with significant coefficients, such as $D Y$ and $D S$ in Model 1. However, the fraction of the variation in consumption growth explained by the state variables is modest. The adjusted $R^{2}$ ranges from $-0.2 \%$ in Model 3 to $7.1 \%$ in Model 1 at the quarterly horizon and from $-0.9 \%$ to $10.3 \%$ at the annual horizon.

A possible explanation for this result is that an unconditional regression does not account for time-varying predictability. To see why this is important, we present in Fig. 2 and Fig. 3 rolling ten-year coefficients from a regression of quarterly and annual consumption growth on the lagged state variables in each model. For the sake of exposition, we focus on the rolling coefficients for $D Y, D S$, and $T S$ in Model 1; RF in Model 2; PE 
and $V S$ in Model 3; and $C P$ and $L V L$ in Model 4. We see that there are substantial periods of time in which the predictive coefficient is significantly different from zero for all state variables, except for $V S$ in Model 3 at the quarterly horizon. A predictive coefficient that is often insignificant, can still hide low-frequency variation that has economic content, however. To see this, note that there are large (and typically significant) differences between the highest and lowest level of the predictive coefficient within the time series of each state variable. When we test for time-variation in risk premia due to these predictive coefficients, we also consider specifications that contrast these extreme periods using dummy variables.

To ascertain that the time-variation in the predictive coefficients is not spurious and has economic content, we run a two-stage test for conditional consumption growth predictability:

$$
\begin{array}{ll}
\text { First stage: } & c_{s+1: s+H}=a_{t, \boldsymbol{z}}^{H}+\boldsymbol{b}_{t, \boldsymbol{z}}^{H \prime} \boldsymbol{z}_{s}+e_{s+1: s+H}, \\
\text { Second stage: } & c_{t+1: t+H}=d_{0}^{H}+d_{1}^{H}\left(a_{t, \boldsymbol{z}}^{H}+\boldsymbol{b}_{t, \boldsymbol{z}}^{H \prime} \boldsymbol{z}_{t}\right)+e_{t+1: t+H}^{c} .
\end{array}
$$

The first stage regresses consumption growth on the lagged state variables over a backward-looking ten-year rolling window using data available up to quarter $t .{ }^{11}$ Hence, the window $s$ runs from $t-40-H+1$ to $t-H$, for $H=1,2,4$. In the second stage, we use the estimated coefficients and the state variables observed at time $t$, that is, $a_{t, \boldsymbol{z}}^{H}+\boldsymbol{b}_{t, \boldsymbol{z}}^{H \prime} \boldsymbol{z}_{t}$, to predict consumption growth from quarter $t+1$ to $t+H$. This setup ensures that we use no forward-looking information when we predict consumption growth in the second stage. The absence of a look-ahead bias is important also, because we use the time-varying coefficients $\boldsymbol{b}_{t, \boldsymbol{z}}^{H \prime}$ to predict returns in the time series. For this reason, our simple setup is preferred over more highly parametrized models that require the full sample for estimation. ${ }^{12}$

If the structure in Eqs. (6) and (7) correctly models the conditional expectation of consumption growth, we should find that $d_{0}^{H}=0$ and $d_{1}^{H}=1$. Since the estimated $b_{t, \boldsymbol{z}}^{H}$ are noisy and subject to misspecification, one would expect to find $d_{0}^{H}>0$ and $d_{1}^{H}<1$ empirically. In other words, it is unlikely that the simple rolling regression fully captures the information set used by investors to form their conditional expectations. However, an interesting question is whether controlling for the rolling relation between the state variables and consumption growth improves the forecast of consumption growth relative to an unconditional model. To this end, we calculate an $R^{2}$ comparison as: $1-\operatorname{var}\left(e_{t+1: t+H}^{c}\right) / \operatorname{var}\left(e_{t+1: t+H}^{u}\right)$. Finally, we present an $R^{2}$ comparison between our model and a specification of Eqs. (6) and (7) that leaves out the state variables. This alternative specification conditions only on the historical mean of consumption growth, which is captured by a time-varying intercept.

Table 2 presents the results. To test significance, we report Newey and West (1987, with $H$ lags) as

\footnotetext{
${ }^{11}$ We extend the sample back by an additional five years by estimating the same regression over an expanding rolling window from five to ten years from 1967 to 1972 . We vary the length of the rolling window in a robustness check.

${ }^{12}$ Section 1 of the Online Appendix shows that our simple method based on rolling window OLS coefficients predicts consumption growth similarly to a model with time-varying parameters estimated using a Kalman filter.
} 
well as bootstrapped $t$-statistics. The bootstrap addresses the errors-in-variables (EIV) concern arising from the two stages of the tests and leads to a relatively conservative inference (see Appendix A for a detailed description of the bootstrap procedure).

At the one-quarter horizon $(H=1), d_{1}^{H}$ is significantly larger than zero for each model ranging from 0.56 (Model 4) to 0.71 (Model 3). Consistent with these large and significant coefficients, the $R^{2}$ s are also large and range from $17 \%$ to $27 \%$. These conditional models thus perform considerably better than the unconditional models of Table 1. Indeed, the (conditional versus unconditional) model comparison $R^{2}$ ranges from $11 \%$ to $25 \%$. In the last row, we see that the conditional model also outperforms by a large margin the conditional model that excludes the state variables, given model comparison $R^{2}$ s ranging from $15 \%$ to $24 \%$. These findings imply that quarterly consumption growth is more predictable when you account for the time-varying relation between consumption growth and the state variables. ${ }^{13}$ The results at the semiannual $(H=2)$ and annual $(H=4)$ horizons are qualitatively similar, though a bit weaker. This finding suggests that the two-stage predictive approach worsens slightly as the horizon becomes longer. At both horizons, however, we can conclude that the state variables predict consumption growth significantly and in an economically important, time-varying way.

In the following, we assume the estimated coefficients $\widehat{\boldsymbol{b}_{t}^{H}}=\left(\widehat{b_{t, z_{1}}}, \ldots, \widehat{b_{t, z_{K}}^{H}}\right)$ suitably proxy for the vector of time-varying SDF coefficients $\boldsymbol{b}_{t, \boldsymbol{z}}=\left(b_{t, z_{1}}, \ldots, b_{t, z_{k}}\right)$ from Eq. (1). Thus, we use a simple, backward-looking, empirical measure for the time-variation in investor's risk aversion to each state variable. The ICAPM predicts that this time-variation is mirrored in the risk premium investors require for exposure to the state variables.

\section{Measuring state variable risk premia}

Following recent literature, we estimate risk premia by running stock-level cross-sectional regressions of quarterly returns on historical exposures to innovations in the state variables. Among others, Litzenberger and Ramaswamy (1979) and Ang, Liu, and Schwarz (2020) contend that stock-level tests are more efficient than portfolio-level tests. While tests with individual stocks are plausibly more subject to EIV (due to noise in estimated exposures), the much wider cross-section of true exposures should more than offset this shortcoming. For the sake of robustness, we also present state variable risk premia estimated by sorting stocks into portfolios. In the following, we present a brief overview of our method, which closely follows Boons (2016).

\footnotetext{
${ }^{13}$ Table OA.2 in the Online Appendix shows that the predictive power of the state variables is robust to controlling for lags of consumption growth.
} 


\subsection{Innovations as risk factors}

Following Campbell (1996), state variables are assumed to follow a first-order vector auto-regression. The $\operatorname{VAR}(1)$ uses only historical data at each point in time, such that the betas in quarter $t$ could be estimated in real time. For each collection comprising the stock market portfolio and a given set of state variables, $\boldsymbol{f}_{t}=\left(r_{t, m}, \boldsymbol{z}_{t}^{\prime}\right)^{\prime}$, we estimate $\boldsymbol{f}_{s}=\boldsymbol{A}_{t, 0}+\boldsymbol{A}_{t, 1} \boldsymbol{f}_{s-1}+\boldsymbol{\epsilon}_{s}$ for $s=1, \ldots, t$. The residuals $\boldsymbol{\epsilon}_{s}$ are orthogonalized from the market return, $r_{t, m}$, and we scale them to have the same variance as $r_{t, m}$. From this point forward, $\boldsymbol{\epsilon}_{s}$ denotes the transformed innovations that are used as risk factors in the asset pricing model in period $t$. The correlations between these risk factors are generally weak $(<0.20)$, such that there is no need to orthogonalize the state variables from each other. ${ }^{14}$ Our tests thus provide direct evidence on the conditional sign-consistency between the cross-sectional risk premium $\lambda_{t+1, z_{k}}$ and the SDF coefficient $b_{t, z_{k}}$. Recall also that the effect of time-variation in $b_{t, z_{k}}$ is magnified by the conditional variance of the state variable. To measure this conditional variance, denoted $\sigma_{t, z_{k}}^{2}$, we estimate a $\operatorname{GARCH}(1,1)$ model for the full sample $\operatorname{VAR}(1)$ residuals for each state variable $z_{k}$.

\subsection{Conditional exposures}

We start with all common stocks listed on the NYSE, Amex, and Nasdaq, but exclude microcaps (stocks with market cap below the 20th percentile on the NYSE). This cutoff ensures that our results are not driven by the smallest of stocks, which are illiquid, volatile, and less likely to be in the investible set of the typical investor. ${ }^{15}$ Elton, Gruber, and Urich (1978) and Cosemans, Frehen, Schotman, and Bauer (2015), among others, show that exposures to non-traded factors are often small and hard to estimate. Therefore, we run a weighted least squares (WLS) regression over all observations available at time $t$ to estimate a stock's market beta, $\beta_{t, i, m}$, and exposure to the state variables, $\boldsymbol{\beta}_{t, i, \boldsymbol{z}}$ (see Eqs. (7) and (8) in Boons, 2016). We use an expanding window of returns with an exponential decay in the weights. The expanding window ensures that as much information as possible is used, and an exponential decay in the weights ensures the timeliness of the estimated betas, which is important as risk exposures of individual firms can vary over time. We shrink these betas to the cross-sectional mean following Vasicek (1973).

\subsection{Cross-sectional regressions}

Our main interest in this paper is in analyzing conditional state variable risk premia $\boldsymbol{\lambda}_{t+1, \boldsymbol{z}}$, which we estimate in each quarter by running a Fama and MacBeth (1973) cross-sectional regression of quarterly returns in $t+1$ on lagged historical market beta, $\beta_{t, i, m}$, and exposure to innovations in the state variables of a particular model, $\boldsymbol{\beta}_{t, i, z}$ :

$$
r_{t+1, i}=\lambda_{t+1,0}+\lambda_{t+1, m} \beta_{t, i, m}+\boldsymbol{\lambda}_{t+1, \boldsymbol{z}}^{\prime} \boldsymbol{\beta}_{t, i, \boldsymbol{z}}+v_{t+1, i}, i=1, \ldots, N_{t}
$$

\footnotetext{
${ }^{14}$ This orthogonalization could add noise through the arbitrary ordering of the state variables.

${ }^{15}$ We exclude financials and firms with negative book equity, as is common in the literature, and require at least four out of the last five years of returns to be available for a stock to be included in quarter $t$.
} 
We estimate the state variable risk premia for the four multi-factor models introduced in Section 3.1. The estimation of the exposures implies an initial burn-in period of five years. As a result, the sample for our asset pricing tests consists of 203 quarters from the second quarter of 1967 to the fourth quarter of 2017.

Table 3 presents summary statistics for the risk premia on each of the three state variables in each of the four models. Recall that these state variable risk premia represent the return of a mimicking portfolio with unit conditional exposure to the state variable of interest in each quarter $t$ (and an exposure of zero to all other factors in the model). The unconditional risk premia for $T S, R F, V S$, and $L V L$ are economically large and marginally significant with absolute Sharpe ratios ranging from 0.24 to 0.30 . Given our focus on relatively big stocks, it is perhaps unsurprising that these Sharpe ratios are slightly smaller in magnitude than what is reported in Boons (2016). Our main interest in this paper is to understand whether these unconditional estimates hide important variation over time, for those state variables that are priced unconditionally as well as those that are not.

\subsection{Inference}

The cross-sectional regression in Eq. (8) is subject to EIV, because the independent variables are unobserved exposures that need to be pre-estimated for each stock in a time-series regression. This time-series regression, in turn, regresses actual returns on VAR-innovations of state variables that are themselves preestimated. While EIV likely biases the unconditional risk premiums towards zero, it is not clear why EIV would bias conditional risk premia in a way that mimics the time-variation (and, in particular, the signswitches) that we document in this paper. Having said that, it is important to correct the standard errors of our estimates for EIV. To do so, we estimate standard errors in all our conditional asset pricing tests using a bootstrap exercise that replicates our analysis 1,000 times on artificial block-resampled data (see Appendix A for more detail). Also, we sort stocks into equal-weighted or value-weighted quintile portfolios using their conditional exposures to the state variables. We then use the return of the high-minus-low quintile portfolio as an alternative measure of the state variable risk premium. The idea is that some stocks will surely be assigned to the wrong portfolio, resulting in conservative inference under the null of cross-sectional pricing ability (Boguth and Kuehn, 2013; Ang, Liu, and Schwarz, 2020). Finally, we perform two simulation studies, which are described in detail in Appendix B. First, we assume that an unconditional ICAPM holds to assess whether our empirical design has good size properties. Second, we assume that a conditional ICAPM holds to determine the power of our tests.

\section{Time-variation in state variable risk premia}

In this section, we test the conditional asset pricing implications of state variable risk. First, the ICAPM implies that the lagged relation between a state variable and consumption growth predicts the risk premium for that state variable with a positive sign. Second, the ICAPM implies that this effect is magnified when the conditional variance of the state variable is high. 


\subsection{Time-varying relation between state variables and consumption growth}

We run pooled predictive regressions of the risk premium for a state variable on the lagged predictive coefficient between that state variable and consumption growth:

$$
\lambda_{t+1: t+H, z_{k}}=g_{0}+g_{1} b_{t, z_{k}}^{H}+\varepsilon_{t+1: t+H, z_{k}},
$$

where $\lambda_{t+1: t+H, z_{k}}$ is an $H$-quarter overlapping return (calculated by compounding the return of the FamaMacBeth cross-sectional regression portfolio for each state variable $k$ in a particular model $\boldsymbol{z}$ ). Besides the econometric advantage of increasing power, the economic motivation for this pooled specification is that in our model the time-variation in risk premia is driven by the strength of the relation between a state variable and consumption growth at a given point in time. This hypothesis is not specific to a given state variable nor to a collection of state variables in a particular multi-factor model. However, to not bias our results in favor of state variables that are included in more than one benchmark model (i.e., $D Y, D S$, and $T S$ ), we include in the pool only the following eight state variable risk premia: $\lambda_{t+1, D Y}, \lambda_{t+1, D S}$, and $\lambda_{t+1, T S}$ from Model $1 ; \lambda_{t+1, R F}$ from Model $2 ; \lambda_{t+1, P E}$ and $\lambda_{t+1, V S}$ from Model 3 ; and, $\lambda_{t+1, C P}$ and $\lambda_{t+1, L V L}$ from Model 4 . To ascertain that our results are driven by time-variation in risk premia, rather than variation in unconditional risk premia across state variables, we also consider specifications with state variable fixed effects.

Table 4 presents annualized coefficient estimates for horizons of $H=1,2,4$ quarters. For each estimate, we present $t$-statistics using both asymptotic standard errors following Driscoll and Kraay (1998), which are robust to heteroscedasticity and rather general forms of cross-sectional and temporal dependence when the time dimension becomes large, and block-bootstrapped standard errors (see Appendix A).

To facilitate interpretation and reduce the noise in the estimated $b_{t, z_{k}}^{H}$, we present in the first column estimates from a regression that substitutes in Eq. (9) a dummy variable that equals one when the predictive coefficient, $b_{t, z_{k}}^{H}$, is positive: $I_{b_{t, z_{k}}^{H}>0}$. The coefficient estimate on this dummy is positive and economically large at all horizons. The estimate implies an increase in the risk premium for a state variable - when the predictive coefficient between that state variable and future consumption growth is positive rather than negative - ranging from a marginally significant $3.93 \%$ at the quarterly horizon to a significant $6.51 \%$ at the annual horizon. Comparing these numbers to the estimated intercept of about $-2.5 \%$, we see that variation in $b_{t, z_{k}}^{H}$ can translate to changes in the sign of state variable risk premia.

To ascertain that this result is due to variation in the time series, rather than unconditional variation across state variables, we present in the second column estimates from a regression that substitutes a dummy variable that equals one when the predictive coefficient is above the time series median for a given state variable: $I_{b_{t, z_{k}}^{H}}>$ median. We find that the coefficient estimate on $I_{b_{t, z_{k}}^{H}}>$ median is statistically significant at all horizons, ranging from $5.16 \%$ at the semi-annual horizon to $6.31 \%$ at the annual horizon. Combining these numbers with the estimated intercepts, our results imply that, on average, when the predictive coefficient for consumption growth for a state variable is above rather than below its time-series median, the state variable 
risk premium increases from about $-3 \%$ to $3 \%$. Given that the standard deviation of the average state variable risk premium is close to $15 \%$ (over the full sample, as reported in Table 3 , as well as when $b_{t, z_{k}}^{H}$ is above and below median), these estimates imply a change in Sharpe ratio of about 0.4. This number is in the same order of magnitude as the Sharpe ratio of the aggregate stock market. This simple test thus suggests that the time-variation in state variable risk premia is economically large.

This suggestion is confirmed in the pooled regressions of column three, for which we regress risk premia on the raw predictive coefficients, $b_{t, z_{k}}^{H}$. We see that the coefficient estimates are positive and (marginally) significant at all horizons. Column four shows similar estimates from a regression with fixed effects. The estimates imply an increase in the risk premium for a state variable of about $2.5 \%$ at the quarterly horizon and about $3 \%$ at the annual horizon for a standard deviation increase in $b_{t, z_{k}}^{H}$. These increases are large compared to unconditional risk premia that range from $0.2 \%$ to $4.5 \%$ in absolute magnitude across the state variables (see Table 3 ).

In the remaining four columns of the table, we run the pooled regression of risk premia on $I_{b_{t, z_{k}}^{H}}>$ median for each of the four separate models. Model 1 uses the left-hand-side risk premia $\left(\lambda_{t+1, D Y}, \lambda_{t+1, D S}, \lambda_{t+1, T S}\right)^{\prime}$, Model 2 uses $\left(\lambda_{t+1, D Y}, \lambda_{t+1, D S}, \lambda_{t+1, R F}\right)^{\prime}$, Model 3 uses $\left(\lambda_{t+1, T S}, \lambda_{t+1, P E}, \lambda_{t+1, V S}\right)^{\prime}$, and Model 4 uses $\left(\lambda_{t+1, D Y}, \lambda_{t+1, C P}, \lambda_{t+1, L V L}\right)^{\prime}$. In each model and at all horizons, the coefficient estimate is positive and economically meaningful, although there is some variation in magnitude and significance. For instance, at the annual horizon, the coefficient estimate is large and significant in Models 1 and 4, at $7.63 \%$ and $6.20 \%$ respectively, which is relative to a marginally insignificant $3.89 \%$ and $3.78 \%$ in Models 2 and 3.

We conclude that risk premia in the pool of state variables are varying over time as predicted by the ICAPM: when a state variable predicts consumption growth strongly relative to its own history, its risk premium increases. In Table OA.3 in the Online Appendix, we show that this conclusion is robust when we split the sample into two halves at the end of 1990. The coefficient estimate on the above median dummy (redefined using the median in each subsample) is significant both pre- and post-1990, at $8.66 \%$ and $3.81 \%$, respectively. Although these estimates suggest a larger effect in the earlier subsample, the regression using the raw predictive coefficient, $b_{t, z_{k}}^{H}$, implies that state variable risk premia increase in both subsamples by about $2.4 \%$ for a standard deviation increase in $b_{t, z_{k}}^{H}$. Furthermore, the first simulation experiment in Appendix B suggests that our evidence is unlikely to be spurious. We find that our method does not over-reject the null of no time-variation in state variable risk premia in an unconditional ICAPM world. The second simulation experiment, which assumes a conditional ICAPM world in which state variables predict consumption growth with time-varying coefficients and risk premia are also time-varying, suggests that our method has power. In this experiment, the null of no time-variation is rejected in about $80 \%$ of the simulations. 


\subsection{Conditional variance of the state variables}

The ICAPM predicts that the time-variation in state variable risk premia documented above is magnified when the conditional variance of a state variable is large. The intuition is that investors want a larger compensation for a unit exposure to a state variable when there is more risk in absolute magnitude. ${ }^{16}$ To test this implication, we extend the pooled predictive regressions to include the interaction effect between risk aversion for a state variable, $b_{t, z_{k}}^{H}$, and the $\operatorname{GARCH}(1,1)$ conditional variance of a state variable, $\sigma_{t, z_{k}}^{2}$ :

$$
\lambda_{t+1: t+H, z_{k}}=g_{0}+g_{1} b_{t, z_{k}}^{H}+g_{2} \sigma_{t, z_{k}}^{2}+g_{3} \sigma_{t, z_{k}}^{2} \times b_{t, z_{k}}^{H}+\varepsilon_{t+1: t+H, z_{k}} .
$$

The coefficient $g_{1}$ captures the effect on risk premia of a time-varying relation between the state variable and future consumption growth, and the ICAPM predicts that this coefficient is positive. The new coefficients $g_{2}$ and $g_{3}$ capture the effect on risk premia of a change in conditional variance, which is standardized in the time series for each state variable $z_{k}$. Given that our state variable risk premia vary in sign (in both the cross-section and time series), there is no theoretical guidance on the unconditional effect captured by $g_{2}$. The ICAPM predicts that the coefficient on the interaction effect, $g_{3}$, is positive, however. If a state variable predicts consumption growth with a positive sign, its risk premium should increase in the conditional variance of the state variable. In addition to the continuous specification of Eq. (10), we also estimate a dummy specification in which we replace $b_{t, z_{k}}^{H}$ with the indicator $I_{b_{t, z_{k}}^{H}>0}$ and $\sigma_{t, z_{k}}^{2}$ with the indicator $I_{\sigma_{t, z_{k}}^{2}}>$ median In this specification, the ICAPM predicts that $g_{2}<0$ and $g_{3}>0 .{ }^{17}$ Panel A of Table 5 presents the coefficient estimates at the annual horizon $(H=4)$.

We see that the coefficient estimates are consistent in sign with the ICAPM predictions. To facilitate interpretation, we present in Panel B the predicted state variable risk premium from the regression in four different cases. These predictions evaluate the joint effect and joint significance of time-variation in $b_{t, z_{k}}^{H}$ and $\sigma_{t, z_{k}}^{2}$. These joint predictions are attractive theoretically, because the ICAPM indicates that it is the product of these two terms that determines risk premia. In case one, the predictive relation between the state variable and future consumption growth is negative and the conditional variance of the state variable is high. This case is defined by setting $b_{t, z_{k}}^{H}$ equal to one standard deviation below the mean (in the pool) and $\sigma_{t, z_{k}}^{2}$ equal to one standard deviation above the mean. In case two, $b_{t, z_{k}}^{H}$ is also one standard deviation below the mean, but $\sigma_{t, z_{k}}^{2}$ is at the mean. In case three, $b_{t, z_{k}}^{H}$ is one standard deviation above the mean and $\sigma_{t, z_{k}}^{2}$ is at the mean. In case four, we set both $b_{t, z_{k}}^{H}$ and $\sigma_{t, z_{k}}^{2}$ equal to one standard deviation above their respective

\footnotetext{
${ }^{16}$ If the conditional variances of the state variables contain information about future consumption growth not contained in their levels, the conditional variances are also candidate risk factors in an ICAPM. However, Table OA.4 in the Online Appendix shows that the variances do not help to predict consumption growth in our conditional test when controlling for the composite predictor of consumption growth based on the levels of the state variables. Therefore, we focus in this paper on the interaction between time-variation in the risk aversion for and conditional variance of the state variables.

${ }^{17}$ We do not focus on the indicator $I_{b_{t, z_{k}}^{H}}>$ median here, because the interaction effect depends on the sign of $b_{t, z_{k}}^{H}$, not the relative magnitude in the time series. For the same reason, we prefer to interpret the evidence from pooled regressions without fixed effects in the context of the ICAPM.
} 
means. The ICAPM implies that the predicted risk premium increases monotonically from case one $(L H)$ to case four $(H H)$. We present $t$-statistics for predicted risk premia using both asymptotic Driscoll and Kraay (1998) and block-bootstrapped standard errors (see Appendix A).

Looking at the four cases in Panel B, we see in both specifications that the coefficient estimates jointly imply economically large and statistically significant variation in risk premia. In the continuous specification, the predicted risk premium for a state variable increases monotonically from a significantly negative $-4.36 \%$ when $b_{t, z_{k}}^{H}$ is low and $\sigma_{t, z_{k}}^{2}$ is high (case one) to a significantly positive $4.73 \%$ when both $b_{t, z_{k}}^{H}$ and $\sigma_{t, z_{k}}^{2}$ are high (case four). In the dummy specification, the increase is even larger from $-4.89 \%$ to $5.59 \%$. The $H H-L H$ difference between these two extreme cases, measuring the total variation in state variable risk premia, is economically large and significant at $9.09 \%$ (continuous specification) and $10.49 \%$ (dummy specification). These differences are only slightly smaller at $8.74 \%$ when including fixed effects, which suggests that the largest part of the variation we document is in the time series. To see the marginal impact of conditional variance, note that the coefficient estimate on the interaction term in the dummy specification $\left(g_{3}\right)$ is economically large and significant at $8.09 \%$ ( $7.84 \%$ with fixed effects). This estimate represents the difference-in-difference: $(H H-L H)-(H L-L L)$, which implies that the spread in risk premia between periods when $b_{t, z_{k}}^{H}$ is positive versus negative increases by about $8 \%$ when conditional variance of the state variable is high relative to when it is low. This diff-in-diff sums the net effect of a change in conditional variance when $b_{t, z_{k}}^{H}$ is high (the $H H-H L$ difference of $5.11 \%$ ) and low (the $L L-L H$ difference of $2.98 \%$ ).

In Table OA.5 in the Online Appendix, we present results for the quarterly and semi-annual horizon. The total variation in state variable risk premia is large also at these alternative horizons. At the quarterly horizon, there is some variation in magnitude: the $H H-L H$ difference ranges from an insignificant $5.5 \%$ to a significant $8.4 \%$ (depending on the specification). At the semi-annual horizon, the $H H-L H$ difference is significant at about $9 \%$ in all specifications and the predicted risk premium increases monotonically from case one to case four. ${ }^{18}$ We conclude that time-variation in the conditional variance of a state variable interacts with time-variation in risk aversion for that state variable. This interaction effect magnifies timevariation in the state variable risk premium, as predicted by the ICAPM, although it does so most robustly at horizons longer than a quarter. This finding is interesting in light of the lack of conclusive evidence for a positive relation between conditional volatility and future stock market returns (in the large literature on the risk-return trade-off) as well as between conditional volatility and a range of traded factors (in the recent literature on volatility timing). ${ }^{19}$

\footnotetext{
${ }^{18} \mathrm{We}$ also show in this table that our results are not sensitive to the choice of focusing on the set of eight unique state variables. We find by and large similar effects when we run the pooled regression of Eq. (10) using all 12 state variables.

${ }^{19}$ Campbell (1987) finds a negative relation between stock market volatility and returns, whereas French, Schwert, and Stambaugh (1987) find an insignificant or positive relation. Subsequent papers also produce mixed evidence on the sign of the risk-return trade-off for the market, with the evidence being sensitive to the chosen method and sample period. Barroso and Santa-Clara (2015) and Moreira and Muir (2017) show that for a number of traded factors, returns are unrelated or negatively related to past volatility.
} 


\subsection{Macro-uncertainty}

In this subsection, we ask whether state variable risk premia rise during times of high macro-uncertainty. This question is motivated by the fact that a large share of the time-variation in the conditional variance of state variables is common. For instance, their first principal component explains about half of the total variation. Given this common variation and given that the state variables contain forward-looking information about consumption growth, the conditional variance of state variables should be correlated to macro-uncertainty.

We do not aspire to contribute to the growing literature on measuring uncertainty (see Jurado, Ludvigson, and Ng, 2015; Baker, Bloom, and Davis, 2016). Rather, we use the conditional variance of consumption growth as a simple proxy of macro-uncertainty. From our two-stage setup for consumption growth predictability in Eqs. (6) and (7), we measure the conditional variance by estimating a $\operatorname{GARCH}(1,1)$ model for the innovations:

$$
e_{t+1: t+H}^{*}=c_{t+1: t+H}-\left(d_{0}^{H}+d_{1}^{H}\left(a_{t, \boldsymbol{z}}^{H}+\boldsymbol{b}_{t, \boldsymbol{z}}^{H \prime} \boldsymbol{z}_{t}\right)\right)
$$

which we denote $\sigma_{t, H}^{2, *}$. This measure ensures consistency in the way we measure the conditional expectation and variance of consumption growth. To assess the sensitivity of our results to conditioning on the state variables, we also construct a second measure of conditional variance by estimating a $\operatorname{GARCH}(1,1)$ model for de-meaned consumption growth, $e_{t+1: t+H}^{* *}=c_{t+1: t+H}-\mu_{c}$, which we denote $\sigma_{t, H}^{2, * *}$.

To start, Fig. 4 plots the conditional variance of consumption growth $\left(\sigma_{t, 1}^{2, * *}\right)$ versus the conditional variance of the eight state variables, which we aggregate either by (i) taking an average across state variables or (ii) extracting the first principal component. We see several periods when both conditional variances (of the state variables and of consumption growth) are high. If these are the periods that matter most to investors, macro-uncertainty should largely subsume the impact of the conditional variance of the state variables on state variable risk premia.

We first ask whether macro-uncertainty magnifies time-variation in state variable risk premia in the same way that the conditional variance of the state variables does. To this end, we substitute each of the two measures of the conditional variance of consumption growth in the pooled predictive regression of Eq. (10). As before, we predict that the coefficient on the interaction effect, $g_{3}$, is positive. If a state variable predicts consumption growth with a positive sign, its risk premium should increase when macro-uncertainty is high. To facilitate interpretation and inference, we focus on the dummy specification in which we replace $b_{t, z_{k}}^{H}$ with the indicator $I_{b_{t, z_{k}}^{H}>0}$ and $\sigma_{t, H}^{2}$ with the indicator $I_{\sigma_{t, H}^{2}>\text { median }}{ }^{20}$ Table 6 presents the results for the annual horizon $(H=4)$.

Looking at the predicted risk premium in the four cases presented in Panel B, we see that the coefficient estimates imply economically large and statistically significant variation in state variable risk premia associ-

\footnotetext{
${ }^{20}$ We present largely similar results for the continuous specification in Tables OA.6 and OA.7 in the Online Appendix.
} 
ated with macro-uncertainty. For instance, for the first measure of the conditional variance of consumption growth, the predicted risk premium increases monotonically from a significantly negative $-4.87 \%$ when $b_{t, z_{k}}^{H}$ is low and $\sigma_{t, H}^{2, *}$ is high (case one) to a significantly positive $4.51 \%$ when both $b_{t, z_{k}}^{H}$ and $\sigma_{t, H}^{2, *}$ are high (case four). For both measures of the conditional variance of consumption growth, the total variation in risk premia (the $H H-L H$ difference) is large and significant at about $9.3 \%$. This variation is mostly over time, because the $H H-L H$ difference remains large and significant at about $7.7 \%$ when we include fixed effects (see Table OA.6 in the Online Appendix). The marginal impact of macro-uncertainty (i.e., the difference-in-difference $(H H-L H)-(H L-L L)$ estimated by the coefficient $\left.g_{3}\right)$ is economically large and marginally significant at $5.7 \%$. This diff-in-diff is about equally driven by periods when $b_{t, z_{k}}^{H}$ is high $(H H-H L \approx 2.7 \%)$ versus low ( $L L-L H \approx 3 \%)$. We conclude that macro-uncertainty predicts returns similarly to the conditional variance of the state variables.

Next, we repeat the regressions of Section 5.2. using measures of the conditional variance of the state variables that control for quarters when one of the two alternative measures of macro-uncertainty is high. To be precise, we set $I_{\sigma_{t, z_{k}}^{2}}>$ median to zero in quarters when $\sigma_{t, H}^{2, *}$ is above median (and analogously for $\sigma_{t, H}^{2, * *}$ ). Table 7 presents the results.

In short, the effect of conditional variance of the state variables is reduced greatly when controlling for macro-uncertainty. For both measures of macro-uncertainty (columns two and three), the coefficient on the dummy $I_{\sigma_{t, z_{k}}^{2}}>$ median increases from about $-3 \%$ to around $-0.4 \%$ when we mute the quarters with high macro-uncertainty. Similarly, the coefficient on the interaction term $I_{b_{t, z_{k}}^{H}>0} \times I_{\sigma_{t, z_{k}}^{2}>\text { median }}$ falls from $8 \%$ to slightly over $1 \%$. Looking at the predicted risk premia, we confirm that the $L H-L L$ and $H H-H L$ differences (between case one and two and case three and four, respectively) are small and insignificant when controlling for macro-uncertainty. We conclude that the bulk of the time-variation in state variable risk premia due to time-variation in variance is not state variable-specific, rather it is common and associated with macro-uncertainty.

\section{Time-varying ICAPM risk premia and benchmark factors}

In this section, we study the time-variation in state variable risk premia in the context of benchmark asset pricing factors. Fama (1996) and Fama and French (2015, p. 3) advocate an "ambitious interpretation" of their factor models as a version of Merton's (1973) ICAPM. In this view, factors such as SMB and HML are not state variable mimicking portfolios, but diversified portfolios that provide different combinations of exposures to the unknown state variables. The factors thus capture the unconditional and conditional expected return effects of state variable risk without having to identify the state variables directly. The unconditional evidence on this interpretation is mixed, which has raised concerns that the ICAPM is used as a fishing license in empirical work (see Maio and Santa-Clara, 2012; Barbalau, Robotti, and Shanken, 2015). More generally, there is a long-standing debate between risk and mispricing as explanations for benchmark 
factors. Using the state variables and the more powerful test of conditional sign consistency, we shed new light on an ICAPM risk-based interpretation of these factors.

To start, we ask whether the time-variation in state variable risk premia is subsumed by the factors in recent asset pricing models, that is, the three-, four-, and five-factor models of Fama and French (1993, FF3M), Carhart (1997, FFCM), and Fama and French (2015, FF5M), respectively. We augment the pooled regression (at the annual horizon, $H=4$ ) to control for contemporaneous exposure to the benchmark factors:

$$
\lambda_{t+1: t+H, z_{k}}=g_{0}+g_{1} b_{t, z_{k}}^{H}+g_{2} \sigma_{t, z_{k}}^{2}+g_{3} \sigma_{t, z_{k}}^{2} \times b_{t, z_{k}}^{H}+\boldsymbol{\beta}_{z_{k}}^{\prime} \boldsymbol{F}_{t+1: t+H}+\varepsilon_{t+1: t+H, z_{k}},
$$

where $\boldsymbol{F}_{t+1}=\left(r_{t+1, m}, r_{t+1, S M B}, r_{t+1, H M L}\right)^{\prime}$ for the FF3M, for instance. To give the benchmark factorsmeasured as the spread in returns between sorted portfolios - a fair chance, we run these pooled regressions for state variable risk premia that are also measured as High-minus-Low portfolio returns. We construct these portfolios by sorting individual stocks (excluding microcaps) into quintiles based on their exposure to a particular state variable. ${ }^{21}$ For brevity, we report in Table 8 the predicted risk premia in the four usual cases from these regressions (using both the continuous and dummy specification). Recall that the ICAPM predicts that risk premia increase monotonically from case one (a negative predictive relation between a state variable and consumption growth and high conditional variance of the state variable) to case four (a positive predictive relation and high conditional variance).

To establish robustness, we first discuss the evidence for the High-minus-Low state variable risk premia without any controls. For the equal-weighted High-minus-Low portfolios in column one, we find qualitatively and quantitatively similar evidence to what we saw before. In both the continuous and dummy specification, the predicted risk premia increase monotonically from case one to case four, consistent with the ICAPM. The total variation in risk premia as measured by the $H H-L H$ difference between the first and fourth case is large and significant at $7.20 \%$ (continuous specification) and $9.49 \%$ (dummy specification). For the valueweighted High-minus-Low portfolios in column six, we also find a large and significant $H H-L H$ difference of $6.10 \%$ in the continuous specification and $5.58 \%$ in the dummy specification. However, comparing case one to case two and case three to case four, we see that the magnifying effect of time-variation in the conditional variance of the state variables is relatively weaker for the value-weighted High-minus-Low portfolios. Thus, time-variation in the conditional variance of the state variables is less informative for risk premia among the largest of stocks.

In the remainder of the table, we present the predicted risk premia controlling for the benchmark factors as in Eq. (12). Let us focus on the difference $H H-L H$. The CAPM does not capture much of this difference, and monotonicity from case one to case four remains. This finding is perhaps unsurprising given that the

\footnotetext{
${ }^{21}$ The evidence for risk premia estimated using Fama-MacBeth cross-sectional regressions is presented in Tables OA.8 and OA.9 in the Online Appendix.
} 
innovations in the state variables are orthogonalized from the market return (see Section 4.1.). The FF3M, including SMB and HML, does a better job and captures about 50\% (40\%) of the total variation in expected state variable risk premia for equal-weighted (value-weighted) High-minus-Low portfolios. However, we see in the different specifications that the $H H-L H$ difference remains marginally significant, which suggests that these state variable risk-sorted portfolios capture a time-varying FF3M alpha. Adding the WML momentum factor to the FF3M has only a small impact on predicted risk premia. In contrast, adding the profitability and investment factors, RMW and CMA, has a considerable impact. The FF5M captures about $80 \%$ of the variation in expected risk premia for equal-weighted portfolios and about $60 \%$ for value-weighted portfolios. The remaining $H H-L H$ difference is small and insignificant (below 2.5\%) and risk premia do not increase monotonically from cases one to case four anymore. We conclude that exposure to the factors in popular asset pricing models captures a large part of the time-variation in expected state variable risk premia. Among the factors, SMB and HML are relatively more important than RMW and CMA, whereas all four of these factors are more important than WML (and the market).

These tests confirm that benchmark factors, and the Fama-French factors in particular, are correlated with the ICAPM-motivated predictor variables. However, these tests do not answer how much variation in expected returns of the factors is implied, for instance, relative to their unconditional average returns. Answering this question is complicated by the fact that there is no obvious one-to-one mapping from the factors to the state variables. To get around this complication, we construct a mimicking portfolio for each state variable. We regress each realized state variable risk premium (either the High-minus-Low equalweighted or value-weighted portfolio return) on the benchmark factors:

$$
\lambda_{t+1: t+H, z_{k}}=\alpha_{z_{k}}+\boldsymbol{\beta}_{\boldsymbol{z}_{k}}{ }^{\prime} \boldsymbol{F}_{t+1: t+H}+\varepsilon_{t+1: t+H, z_{k}},
$$

where $\boldsymbol{F}_{t+1}=\left(r_{t+1, S M B}, r_{t+1, H M L}, r_{t+1, R M W}, r_{t+1, C M A}, r_{t+1, W M L}\right) .{ }^{22}$ We define the maximum correlation mimicking portfolio for state variable $z_{k}: \lambda_{t+1, z_{k}}^{M C M}=\boldsymbol{\beta}_{\boldsymbol{z}_{\boldsymbol{k}}}{ }^{\prime} \boldsymbol{F}_{t+1}$. With these mimicking portfolios in hand, we run the pooled predictive regressions of Eqs. (9) and (10) to quantify how much time-variation in expected returns is implied for these portfolios of the benchmark factors. ${ }^{23}$

These regressions are interesting, because existing evidence on time-variation in expected factor returns is rather scarce and cannot easily distinguish between stories of risk and mispricing. ${ }^{24}$ Formally, we ask

\footnotetext{
${ }^{22}$ Consistent with our focus on annual return predictability throughout, we run this regression at the annual horizon $(H=4)$. In Table OA.10 in the Online Appendix, we present qualitatively and quantitatively similar evidence when we run this regression using quarterly returns.

${ }^{23}$ Note that the coefficient estimates from Eqs. (9) and (10) are consistent even though the eight state variable mimicking portfolios are linear combinations of only five benchmark factors. Furthermore, the standard errors of Driscoll and Kraay (1998) appropriately correct for the correlation between the mimicking portfolios. Table OA.11 shows that our evidence is also robust to running the pooled regressions for smaller subsets of three state variable mimicking portfolios.

${ }^{24}$ Arguably the strongest evidence in favor of predictability is in Haddad, Kozak, and Santosh (2018), who show that longshort characteristics-sorted portfolio returns are predictable by the long-short spread in book-to-market. However, both risk and mispricing can drive variation in valuation ratios (Cochrane, 2011). Our ICAPM-motivated tests also alleviate the concern
} 
whether economically interesting combinations of the benchmark factors contain the conditional expected return effects of state variable risk in an ICAPM.

Panel A of Table 9 presents coefficient estimates for the four different specifications that tease out the role of risk aversion for a state variable, measured as the conditional relation between the state variable and future consumption growth. The coefficient $g_{1}$ is positive, economically large, and significant in all four specifications and for both equal- and value-weighted portfolios. For instance, when regressing the returns of the state variable mimicking portfolios on $b_{t, z_{k}}^{H}$ including fixed effects, the coefficient estimates imply an increase in risk premia of about $2.6 \%(t>2.5)$ on average for a standard deviation increase in $b_{t, z_{k}}^{H}{ }^{25}$ In Panel B, we find again that risk aversion for a state variable interacts in an important way with the conditional variance of a state variable. The predicted risk premia increase monotonically from cases one $(L H)$ to four $(H H)$ and are similar to what we find for the equal-weighted and value-weighted portfolios in Table 8. For instance, in the continuous specification, the $H H-L H$ difference is significant for both equal- and value-weighted portfolios at about $6.5 \%$. Compared to an annual standard deviation of $15 \%$, this difference represents an economically large amount of time-variation. In fact, this time-series difference is about as large as the spread in unconditional average returns across the different mimicking portfolios. Thus, we conclude that the expected returns to economically interesting portfolios of the benchmark factors contain significant conditional variation.

In Table OA.12 in the Online Appendix, we present the mimicking portfolio weights and $R^{2}$ s from the regression in Eq. (13). Two results stand out. First, the benchmark factors capture about a third of the variation in the state variable risk premia. Thus, even though these factors do not explain the majority of the variation in realized state variable risk premia, the conditionally expected returns of portfolios of these factors do contain by and large the same time-variation as the state variable risk premia. ${ }^{26}$ Second, multiple state variables load significantly on the Fama-French factors SMB, HML, RMW, and CMA in the mimicking portfolio. In contrast, the realized state variable risk premia are largely uncorrelated to the WML momentum factor. Thus, we conclude that the Fama-French factors contain the conditional expected return effects implied by the pricing of state variable risk in an ICAPM, as advocated by Fama and French.

\section{Additional evidence}

In this section we discuss additional evidence for which results are reported in the Online Appendix.

that factor return predictability could be spurious. For instance, Novy-Marx (2014) finds that variables unrelated to the stock market, such as celestial phenomena, predict long-short factor returns.

${ }^{25}$ The coefficient estimates are consistent in sign, but about twice as large in the models without fixed effects. This finding suggests that about half of the variation in expected risk premia in the pool is driven by unconditional differences across the state variable mimicking portfolios in a way that is consistent with the unconditional implications of the ICAPM. Perhaps unsurprisingly, the unconditional effects for portfolios of the benchmark factors are larger than what we find for the state variable risk premia in Table 3.

${ }^{26}$ Table OA.13 in the Online Appendix confirms that the unexplained part of the state variable risk premia, $\lambda_{t+1, z_{k}}-\boldsymbol{\beta}_{\boldsymbol{z}_{\boldsymbol{k}}}{ }^{\boldsymbol{}} \boldsymbol{F}_{t+1}$ from Eq. (13), is unpredictable. 


\subsection{Principal components and Ludvigson and $\mathrm{Ng}$ (2009) factors}

We ask whether our conclusions extend to alternative combinations of state variables. To start, we extract principal components from our original set of eight state variables. The first alternative model we consider contains the first two principal components, which together capture $68 \%$ of the total variation. The second alternative model adds the third principal component, which captures an additional $14 \%$ of the variation. The third alternative model uses the first three macro-factors of Ludvigson and $\mathrm{Ng}$ (2009). These factors are popular in the macro-literature and are extracted from a large data set of 132 macroeconomic time series. ${ }^{27}$

In Table OA.14 we present results from the two-stage test for conditional consumption predictability (see Eqs. (6) and (7)) for each of the three alternative models. We see that the principal components of our state variables as well as the macro-factors help to predict consumption growth in the second stage of the test. For instance, at the quarterly horizon, the $R^{2}$ ranges from $15 \%$ for the two principal components to $23 \%$ for the Ludvigson and $\mathrm{Ng}$ (2009) factors. The $R^{2}$ comparisons (relative to an unconditional model with these alternative state variables as well as relative to a model conditioning only on past average consumption growth) are similarly large. These results suggest that controlling for the time-varying relation between these alternative state variables and consumption growth, helps to predict consumption growth going forward.

The ICAPM then implies that risk premia for exposure to innovations in these alternative state variables are also time-varying. To test this implication, we estimate these risk premia following the cross-sectional regression approach of Section 4.3. We then run the pooled regression of Eq. (10) separately for the (set of two or three) risk premia in each alternative model. We present the results in Table OA.15. For brevity, we focus on the predicted risk premium in four cases. We see a large and significant $H H-L H$ difference in predicted risk premia, ranging from about $8 \%$ to $19 \%$ in the models with fixed effects. We conclude that risk premia for these alternative state variables are importantly time-varying consistent with conditional implications from the ICAPM. We further see that the $H H-L H$ difference typically follows from a monotonic increase in the risk premium from case one to case four. Thus, both the conditional relation between the alternative state variables and consumption growth as well as the conditional variance of these alternative state variables are contributing to the time-variation in risk premia.

\subsection{Alternative measures of macroeconomic growth}

We ask whether our results are robust to the proxy for the time-varying coefficients of the SDF (see Eq. (1)). Before, we measured the conditional relation between a state variable and the consumption-investment opportunity set using its predictive coefficient for consumption growth estimated over a ten-year rolling window. In Table OA.16 we show similar amounts of time-variation in state variable risk premia when we

\footnotetext{
${ }^{27}$ We thank the authors for sharing this data on their website. The first factor loads heavily on measures of employment and production; the second factor loads heavily on several interest rate spreads; and, the third factor loads most heavily on measures of inflation and price pressure.
} 
vary the length of the rolling window from 7.5 to 15 years. Next, we substitute three measures of general macroeconomic activity for consumption growth to estimate $b_{t, z_{k}}^{H}$ in Eq. (6): real GDP growth, seasonally adjusted industrial production growth, and the first principal component of the three macro-series (explaining $67 \%$ of the total variation).

In Table OA.17, we show that our state variables significantly predict these alternative measures of growth in an out-of-sample test. Thus, the predictive coefficients for these alternative measures of macroeconomic growth should also be good proxies for the SDF coefficients that guide time-variation in state variable risk premia. In Table OA.18, we establish that this is indeed the case. In Panel A, we run the pooled regression of Eq. (9) with $I_{b_{t, z_{k}}^{H}}>$ median, which is a direct and simple test of whether risk premia vary over time at the state variable level. We see that the coefficient is significant, ranging from $4 \%$ for IPG to $5 \%$ for GDP. This result implies that a state variable risk premium increases on average by $4 \%$ to $5 \%$ over time when the relation between that state variable and one of the alternative measures of growth is historically strong. In Panel $\mathrm{B}$, we show that the conditional variance of the state variables further magnifies this time-variation in state variable risk premia. We thus conclude that our results are consistent with conditional asset pricing implications from a model in which general macroeconomic or recession risk is priced.

\subsection{The conditional variance of state variables}

Throughout, we have measured conditional variance by estimating a GARCH(1,1) model for VAR(1) residuals in the state variables that are estimated over the full sample. Table OA.19 uses the square of $\operatorname{VAR}(1)$ residuals that are estimated at each point in time using only historical information (see Section 4.1.). We see that our conclusions on the magnifying effect of conditional variance are robust.

\section{Conclusion}

In this paper, we show that risk premia for exposure to state variables are substantially time-varying. We argue that this variation is driven by time-variation in the predictive relation between the state variables and future consumption growth and is magnified by time-variation in the conditional variance of the state variables. Both effects are consistent with the conditional implications of an ICAPM.

We show that controlling for time-varying coefficients in the relation between the state variables and consumption growth significantly improves consumption growth predictability relative to an unconditional model. Consistent with this time-variation, the risk premium for a state variable is larger in the time series by 0.4 in an annualized Sharpe ratio whenever a state variable predicts consumption growth relatively strongly. This effect is statistically significant, robust, and economically large. Further, we show that this effect strengthens when the conditional variance of a state variable is high. We argue that an important share of the variation in conditional variance is common to all state variables and associated with macrouncertainty. We finally show that portfolios of the Fama-French factors contain the same conditional expected 
return effects as the state variable risk premia, which is consistent with an ICAPM interpretation for these empirical factors.

We contribute most directly to recent literature that tests the unconditional implications of ICAPM-type models, with mixed and inconclusive results so far. Using the broadest possible cross-section of individual stocks, a large set of state variables, and a conditional setup, we raise the bar considerably for the data to be consistent with the model. Given the model's success in explaining the conditional variation in state variable risk premia, our findings strengthen the case for time-varying, rational risk premia that drive the predictability of returns. We leave open the interesting question of what drives the time-variation in the relation between the different state variables and the macroeconomy. Candidate factors are monetary policy, the prevalence of supply and demand shocks, and learning by economic agents, among others.

\section{Appendix A. Bootstrap}

The block-bootstrap algorithm designed to deal with EIV consists of the following steps.

1. In each of 1,000 replications, $m=1, \ldots, 1,000$, we construct pseudo-samples for consumption growth and the state variables. We draw with replacement $T_{m}$ five-year blocks from:

$$
\left\{c_{t+1: t+20}^{m}, \boldsymbol{z}_{t+1: t+20}^{m}\right\}, t=s_{1}^{m}, s_{2}^{m}, \ldots, s_{T_{m}}^{m}
$$

where the time indices, $s_{1}^{m}, s_{2}^{m}, \ldots, s_{T_{m}}^{m}$, are drawn randomly from the original time sequence $1, \ldots, T$. The large block size is chosen to ensure that we end up with a reasonably large cross-section of stocks to estimate state variable risk premia in each bootstrap replication. The re-sampling of the CRSP file is described in detail in Step 3 below. ${ }^{28}$ Moreover, this block size preserves the (auto-)correlation structure in the data. We join these blocks to construct a quarterly time series matching the length of our sample from the second quarter of 1962 to the fourth quarter of 2017.

2. For each replication, $m$, we then run the two-stage tests described in Section 3 for the artificial data:

$$
\begin{aligned}
& c_{s+1: s+H}^{m}=a_{t}^{m, H}+\boldsymbol{b}_{t}^{m, H \prime} \boldsymbol{z}_{s}^{m}+e_{s+1: s+H}^{m}, \\
& c_{t+1: t+H}^{m}=d_{0}^{m, H}+d_{1}^{m, H}\left(a_{t}^{m, H}+\boldsymbol{b}_{t}^{m, H \prime} \boldsymbol{z}_{t}^{m}\right)+e_{t+1: t+H}^{m, c},
\end{aligned}
$$

and save the estimates $d_{0}^{m, H}, d_{1}^{m, H}$, and $\boldsymbol{b}_{t}^{m, H}$, for $H=1,2,4$. The bootstrapped standard errors for Table 2 are calculated as the standard deviation of $d_{0}^{m, H}$ and $d_{1}^{m, H}$ over the bootstrap replications. We use the bootstrap estimates, $\boldsymbol{b}_{t}^{m, H}$, to get the bootstrapped standard errors for the remaining tests of the paper.

\footnotetext{
${ }^{28}$ We also run 1,000 replications of a bootstrap with smaller three-year blocks. For this alternative bootstrap exercise, the inference on the predictability of consumption growth is only slightly more conservative than what we report in the paper, whereas the inference on the predictability of state variable risk premia is by and large identical.
} 
3. Using the time indices $s_{1}^{m}, s_{2}^{m}, \ldots, s_{T_{m}}^{m}$ from Step 1 above, we re-sample the returns of all firms $i=$ $1, \ldots, I$ in the CRSP file (excluding microcaps):

$$
\left\{R_{t+1: t+20}^{m}\right\}, t=s_{1}^{m}, s_{2}^{m}, \ldots, s_{T_{m}}^{m}
$$

In each replication, we estimate at the end of quarter $t$ and for each artificial stock $i$ the exposure to innovations in the state variables. These innovations are re-sampled from the innovations in each state variable $z_{k}$ in the data (see Section 4.1.), again using the time indexes from Step 1, above. The exposures are estimated using the WLS-Vasicek procedure described in Section 4.2. We require that an artificial stock has at least 16 out of the last 20 quarters of returns available to be included. Since many stocks have missing returns in the CRSP file, due to late introduction or early exit, the re-sampling reduces the number of firms that satisfy this requirement relative to the data. With the block size of 20 quarters, we end up with about $70 \%$ of the number of firms that we use in the data in each bootstrapped cross-section (about 850 stocks on average relative to 1,100 in the data). This result indicates that the cross-section remains large and, to the extent that this reduction adds noise, this should bias against finding our results to be significant.

4. For $m=1, \ldots, 1,000$ and at the end of each quarter $t$, we then run, for each quarter, the cross-sectional regression of returns on the exposures to the state variables in a particular model:

$$
r_{t+1, i}^{m}=\lambda_{t+1,0}^{m}+\lambda_{t+1, m k t}^{m} \beta_{t, i, m k t}^{m}+\boldsymbol{\lambda}_{t+1, \boldsymbol{z}}^{m \prime} \boldsymbol{\beta}_{t, i, \boldsymbol{z}}^{m}+v_{t+1, i}^{m}
$$

and store the artificial state variable risk premia, $\boldsymbol{\lambda}_{t+1, \boldsymbol{z}}^{m}$.

5. We combine these state variable risk premia with the conditional relation between consumption and the state variables from Step 2, to run the predictive regression described in Section 5. As in Table 4, we first regress the artificial state variable risk premia on the lagged predictive coefficient $\boldsymbol{b}_{t}^{m, H}$ (or the dummy variables derived from this coefficient) using:

$$
\lambda_{t+1: t+H, z_{k}}^{m}=g_{0}^{m}+g_{1}^{m} b_{t, z_{k}}^{m, H}+\varepsilon_{t+1: t+H, z_{k}}^{m}
$$

The timing in the different steps of the bootstrap is consistent with the data. We use the standard deviation of the estimates $\left(g_{0}^{m}, g_{1}^{m}\right)$ over the 1,000 bootstrap replications as the standard error for the predictive regressions in the paper.

6. Similarly, we regress the artificial state variable risk premia on the lagged predictive coefficient $b_{t, z_{k}}^{m, H}$, a measure of conditional variance, and their interaction using:

$$
\lambda_{t+1: t+H, z_{k}}^{m}=g_{0}^{m}+g_{1}^{m} b_{t, z_{k}}^{m, H}+g_{2}^{m} \sigma_{t, H}^{2, m}+g_{3}^{m} \sigma_{t, H}^{2, m} \times b_{t, z_{k}}^{m, H}+\varepsilon_{t+1: t+H, z_{k}}^{m}
$$

where $\sigma_{t, H}^{2, m}$ represents either the conditional variance of a state variable (as in Table 5 ) or of consumption 
(as in Table 6). The bootstrapped conditional variance of consumption growth, denoted $\sigma_{t, H}^{2, m, *}$, is found

by estimating a $\operatorname{GARCH}(1,1)$ model for the innovations $e_{t+1: t+H}^{m, c}$ from Step 2, above. The bootstrapped conditional variance of the state variables, denoted $\sigma_{t, z_{k}}^{2, m}$, is found by estimating a $\operatorname{GARCH}(1,1)$ model for the innovations in the state variables.

Throughout, we use as standard errors the standard deviation of the 1,000 bootstrap estimates. We find that the mean of the bootstrap estimates is biased towards zero when predicting consumption growth in Table 2 and even more so when predicting risk premia in Tables 4,5 , and 6 . The bootstrap bias is to a large extent due to the use of rolling window coefficients estimated over relatively small samples, which introduces noise that accumulates over the different stages of our estimation method. This downward bias suggests that our results likely underestimate the true amount of variation in consumption growth and risk premia.

\section{Appendix B. Simulation analysis}

We conduct two simulations. The first simulation assesses the size of our tests and asks how often we reject the null hypothesis of no time-variation in an unconditional ICAPM world. In this world, the state variables capture a constant risk premium because each state variable predicts consumption growth with a coefficient that is constant over time. The second simulation assesses the power of our tests and asks how often we reject the null hypothesis of no time-variation in a conditional ICAPM world. In this world, the state variable risk premia vary over time, because each state variable predicts consumption growth with a time-varying coefficient. Both simulations use Model 1 as the representative model for the time-series properties of the state variables and are calibrated to quarterly data. Consumption in Model 1 is a function of $D Y, D S$, and $T S$, and its choice as a reference model is consistent with the univariate simulations in Maio and Santa-Clara (2012) and Boons (2016), who use TS as the representative state variable. Finally, to allow for a clearer interpretation of our results and more transparency, we use only diagonal co-variance matrices for residuals and use the same slope coefficients in the consumption process for all three state variables, the same parameters determining the time-series behavior of these slopes, and the same unconditional means for the state variable risk premia.

Setup

Both simulations are based on 15,000 samples of artificial data for the three state variables stacked together in $\boldsymbol{z}_{t+1}^{n}$, with $t=0, \ldots, 223$ and $n=1, \ldots, 15,000$. State variables follow an AR(1) process

$$
\boldsymbol{z}_{t+1}^{n}=\phi_{z}^{\prime} \boldsymbol{z}_{t}^{n}+\boldsymbol{\epsilon}_{t+1, \boldsymbol{z}}^{n}
$$

where the elements in $\phi_{z}$ are set equal to the average of the sample values for $D Y, D S$, and $T S$, and $\boldsymbol{\epsilon}_{t+1, \boldsymbol{z}}^{n}$ has a multivariate normal distribution with zero means, and a co-variance matrix with diagonal elements of $1-\phi_{z} \circ \phi_{z}$, where $\circ$ is the Hadamard product, and zero off-diagonal elements. The drift in Eq. (B.1) is zero 
to take into consideration that the state variables are standardized in the analysis. The initial realization of each state variable is drawn for each pseudo-sample from a standard normal distribution.

In the unconditional ICAPM world, log consumption growth $c_{t+1}^{u, n}$ follows

$$
c_{t+1}^{u, n}=a^{u}+\boldsymbol{b}^{u \prime} \boldsymbol{z}_{t}^{u, n}+e_{t+1}^{u, n}
$$

where $a^{u}$ is set to its sample value, $e_{t+1}^{u, n}$ is sampled from a normal distribution with zero mean and variance set to its sample value, and all elements in $\boldsymbol{b}^{u}$ are set equal to the average absolute slope coefficient in Model 1 (see Table 1).

State variable risk premia $\boldsymbol{\lambda}_{t+1, \boldsymbol{z}}^{u, n}$ are generated from

$$
\boldsymbol{\lambda}_{t+1, \boldsymbol{z}}^{u, n}=\boldsymbol{b}^{u} \times k+\varepsilon_{t+1}^{u, n}
$$

where $k$ is a scaling factor set to 2.5 , which is close to the median of the ratio for $D Y, D S$, and $T S$ of the unconditional risk premium over the slope coefficient in the unconditional consumption predictability regression. $\varepsilon_{t+1}^{u, n}$ is sampled from a multivariate normal distribution with zero means and diagonal covariance matrix in which the variances are equal to the average sample variance of the state variable risk premia of $D Y, D S$, and $T S$.

To simulate data consistent with a conditional ICAPM, we relax the assumption that the intercepts and slopes in the consumption process are fixed, and instead assume that $\boldsymbol{B}_{t+1}^{c, n}=\left(a_{t+1}^{c, n}, \boldsymbol{b}_{t+1}^{c, n \prime}\right)^{\prime}$ follow AR(1) processes. These processes are fitted to the coefficients of the rolling window regressions of consumption growth on DY, DS, and TS in the empirical analysis. In particular, $\boldsymbol{B}_{t+1}^{c, n}$ follows

$$
\boldsymbol{B}_{t+1}^{c, n}=\phi_{\boldsymbol{B}, 0}+\phi_{\boldsymbol{B}, 1} \boldsymbol{B}_{t}^{c, n}+\boldsymbol{v}_{t+1}^{c, n}
$$

where $\phi_{\boldsymbol{B}, 1}$ is set to 0.96 to be consistent with empirical values that range from 0.94 to 0.98 . The elements in $\phi_{\boldsymbol{B}, 0}$ are chosen such that $\boldsymbol{B}_{t+1}^{c, n}$ has the same expected value as its counterpart in the unconditional simulation. $\boldsymbol{v}_{t+1}^{c, n}$ is drawn from a multivariate normal distribution with zero means and diagonal co-variance matrix with variances equal to the average of the sample values. The initial values of $\boldsymbol{B}_{t}^{c, n}$ are drawn from the unconditional distribution implied by Eq. (B.4).

Log consumption growth in the conditional ICAPM, $c_{t+1}^{c, n}$, is then generated as

$$
c_{t+1}^{c, n}=a_{t}^{c, n}+\boldsymbol{b}_{t}^{c, n^{\prime}} \boldsymbol{z}_{t}^{c, n}+e_{t+1}^{c, n}
$$

where $e_{t+1}^{c, n}$ is sampled from a normal distribution with mean zero and variance equal to the average variance in the rolling window regressions of Model 1.

State variable risk premia $\boldsymbol{\lambda}_{t+1, \boldsymbol{z}}^{c, n}$ are generated with

$$
\boldsymbol{\lambda}_{t+1, \boldsymbol{z}}^{c, n}=\boldsymbol{b}_{t}^{c, n} \times k+\varepsilon_{t+1}^{c, n}
$$


where the scaling factor $k$ is set to the same value as in the unconditional simulation, and $\varepsilon_{t+1}^{c, n}$ is sampled from a multivariate normal distribution with zero means and diagonal co-variance matrix with variances equal to their average sample value in Model 1.

Armed with the two simulated data sets, $\left\{\boldsymbol{z}_{t+1}^{n}, \boldsymbol{c}_{t+1}^{u, n}, \boldsymbol{\lambda}_{t+1}^{u, n}\right\}$ and $\left\{\boldsymbol{z}_{t+1}^{n}, \boldsymbol{c}_{t+1}^{c, n}, \boldsymbol{\lambda}_{t+1}^{c, n}\right\}$, we first run the analysis of Table 2 and store the $R^{2}$ comparison of the conditional versus unconditional model. Second, we run the analysis of Table 3 and report the unconditional risk premia averaged over the state variables. Finally, we combine the risk premium estimates from three separate simulations, thereby reducing the unconditional and conditional data sets to 5,000 simulations each, and run the analysis of Table 4 . In this way, the total number of risk premia in the pooled predictive regression is nine, close to the eight we use in the paper. We focus on the specifications with fixed effects using either the dummy $I_{b_{t, z_{k}}^{1}}>$ median or the raw $b_{t, z_{k}}^{1}$.

Results

Table B.1 presents the simulation results. We report the empirical distribution of (i) the $R^{2}$ comparison between unconditional and conditional consumption growth predictability, as reported in Table 2; (ii) the unconditional risk premia, as reported in Table 3; and, (iii) the slope coefficient from the pooled predictive regression of state variable risk premia on the predictive coefficient between a state variable and consumption growth, as reported in Table 4. We focus on coefficient estimates from the quarterly horizon, $H=1$, because the introduction of overlapping observations complicates the simulations unnecessarily. Moreover, we consider both the dummy specification with $I_{b_{t, z_{k}}}>$ median and the continuous specification with $b_{t, z_{k}}$ (including state variable fixed effects).

In the unconditional ICAPM world, over $99 \%$ of the $R^{2}$ comparisons are negative, consistent with the idea that any estimated time-variation in the relation between a state variable and future consumption growth is noise. Therefore, the large increases in $R^{2}$ we present in Table 2 are unlikely in an unconditional ICAPM world. In this unconditional world, the estimated slope coefficient in the pooled predictive regression is centered around zero and significant in only about $5 \%$ of the simulations (in both the dummy and continuous specification). In contrast, in the conditional ICAPM world, $73 \%$ of the $R^{2}$ comparisons are positive, suggesting that consumption growth is predictable. Moreover, more than $98 \%(77 \%)$ of the slope coefficients in the pooled predictive regression are positive (significantly positive) for the dummy specification and $99 \%$ $(88 \%)$ for the continuous specification. Also, the median effects match well what we find in the data: risk premia increase by $3.7 \%$ when $b_{t, z_{k}}$ is above its time-series median (versus $5.2 \%$ in Table 4 ), and by $2.7 \%$ for a one standard deviation increase in $b_{t, z_{k}}$ (versus $2.5 \%$ in Table 4 ). We conclude that our method does not over-reject and has power to distinguish between the unconditional and conditional ICAPM world. In fact, although the simulated state variable risk premia are drawn from a distribution with a positive mean, their variation over time is such that we find positive and significant average risk premia ex post only in $55 \%$ of the simulations. Thus, time-variation in risk premia is a plausible explanation for the conflicting evidence in 
recent unconditional tests of the ICAPM. 


\section{References}

Ang, A., Liu, J., Schwarz, K., 2020. Using stocks or portfolios in tests of factor models. Journal of Financial and Quantitative Analysis 55, 709-750.

Baker, S. R., Bloom, N., Davis, S. J., 2016. Measuring economic policy uncertainty. Quarterly Journal of Economics 131, 1593-1636.

Bansal, R., Kiku, D., Shaliastovich, I., Yaron, A., 2014. Volatility, the macroeconomy, and asset prices. Journal of Finance 69, 2471-2511.

Bansal, R., Yaron, A., 2004. Risks for the long run: A potential resolution of asset pricing puzzles. Journal of Finance 59, 1481-1509.

Barbalau, A., Robotti, C., Shanken, J., 2015. Testing inequality restrictions in multifactor asset-pricing models, Unpublished working paper. Imperial College, London.

Barroso, P., Santa-Clara, P., 2015. Momentum has its moments. Journal of Financial Economics 116, 111-120.

Bergman, Y. Z., 1985. Time preference and capital asset pricing models. Journal of Financial Economics 14, $145-159$.

Boguth, O., Kuehn, L.-A., 2013. Consumption volatility risk. Journal of Finance 68, 2589-2615.

Boons, M. F., 2016. State variables, macroeconomic activity, and the cross section of individual stocks. Journal of Financial Economics 119, 489-511.

Boons, M. F., Duarte, F., de Roon, F., Szymanowska, M., 2020. Time-varying inflation risk and stock returns. Journal of Financial Economics 136, 444-470.

Breeden, D. T., 1979. An intertemporal asset pricing model with stochastic consumption and investment opportunities. Journal of Financial Economics 7, 265-296.

Campbell, J. Y., 1987. Stock returns and the term structure. Journal of Financial Economics 18, 373-399.

Campbell, J. Y., 1996. Understanding risk and return. Journal of Political Economy 104, 298-345.

Campbell, J. Y., 2018. Financial Decisions and Markets: A Course in Asset Pricing. Princeton University Press, Princeton, NJ.

Campbell, J. Y., Cochrane, J. H., 2000. Explaining the poor performance of consumption-based asset pricing models. Journal of Finance 55, 2863-2878. 
Campbell, J. Y., Giglio, S., Polk, C., Turley, R., 2018. An intertemporal CAPM with stochastic volatility. Journal of Financial Economics 128, 207-233.

Campbell, J. Y., Pflueger, C., Viceira, L., 2014. Monetary policy drivers of bond and equity risks, Unpublished working paper. Harvard University, Cambridge.

Campbell, J. Y., Vuolteenaho, T., 2004. Bad beta, good beta. American Economic Review 94, 1249-1275.

Carhart, M. M., 1997. On persistence in mutual fund performance. Journal of Finance 52, 57-82.

Chen, N.-F., Roll, R., Ross, S. A., 1986. Economic forces and the stock market. Journal of Business 59, $383-403$.

Cochrane, J. H., 2005. Asset Pricing. Princeton University Press, Princeton, NJ.

Cochrane, J. H., 2011. Presidential address: Discount rates. Journal of Finance 66, 1047-1108.

Cochrane, J. H., Piazzesi, M., 2005. Bond risk premia. American Economic Review 95, 138-160.

Cooper, I., Maio, P., 2019. Asset growth, profitability, and investment opportunities. Management Science $65,3988-4010$.

Cosemans, M., Frehen, R., Schotman, P. C., Bauer, R., 2015. Estimating security betas using prior information based on firm fundamentals. Review of Financial Studies 29, 1072-1112.

David, A., Veronesi, P., 2013. What ties return volatilities to price valuations and fundamentals? Journal of Political Economy 121, 682-746.

Driscoll, J. C., Kraay, A. C., 1998. Consistent covariance matrix estimation with spatially dependent panel data. Review of Economics and Statistics 80, 549-560.

Elton, E. J., Gruber, M. J., Urich, T. J., 1978. Are betas best? Journal of Finance 33, $1375-1384$.

Epstein, L. G, Zin, S. E, 1989. Substitution, risk Aversion, and the temporal behavior of consumption and asset returns: A theoretical framework. Econometrica 57, 937-969.

Fama, E. F., 1976. Foundations of Finance. Basic Books, New York.

Fama, E. F., 1991. Efficient capital markets: II. Journal of Finance 46, 1575-1617.

Fama, E. F., 1996. Multifactor portfolio efficiency and multifactor asset pricing. Journal of Financial and Quantitative Analysis 31, 441-465.

Fama, E. F., French, K. R., 1993. Common risk factors in the returns on stocks and bonds. Journal of Financial Economics 33, 3-56. 
Fama, E. F., French, K. R., 2015. A five-factor asset pricing model. Journal of Financial Economics 116, $1-22$.

Fama, E. F., MacBeth, J. D., 1973. Risk, return, and equilbrium: Empirical tests. Journal of Political Economy 81, 607-636.

Ferson, W. E., Harvey, C. R., 1991. The variation of economic risk premiums. Journal of Political Economy $99,385-415$.

French, K. R., Schwert, W. G., Stambaugh, R. F., 1987. Expected stock returns and volatility. Journal of Financial Economics 19, 3-29.

Haddad, V., Kozak, S., Santosh, S., 2018. The economics of factor timing, Unpublished working paper. UCLA Anderson School of Management, Los Angeles.

Harvey, C. R., 1988. The real term structure and consumption growth. Journal of Financial Economics 22, $305-333$.

Jagannathan, R., Wang, Z., 1996. The conditional CAPM and the cross-section of expected returns. Journal of Finance 51, 3-53.

Jurado, K., Ludvigson, S. C., Ng, S., 2015. Measuring uncertainty. American Economic Review 105, 11771216.

Kang, J., Pflueger, C. E., 2015. Inflation risk in corporate bonds. Journal of Finance 70, 115-162.

Koijen, R. S., Lustig, H., Nieuwerburgh, S. V., 2017. The cross-section and time series of stock and bond returns. Journal of Monetary Economics 88, 50-69.

Lettau, M., Ludvigson, S., 2001. Resurrecting the (C)CAPM: A cross-sectional test when risk premia are time-varying. Journal of Political Economy 109, 1238-1287.

Lewellen, J., Nagel, S., 2006. The conditional CAPM does not explain asset-pricing anomalies. Journal of Financial Economics 82, 289-314.

Lewellen, J., Nagel, S., Shanken, J., 2010. A skeptical appraisal of asset pricing tests. Journal of Financial Economics 96, 175-194.

Litzenberger, R. H., Ramaswamy, K., 1979. The effect of personal taxes and dividends on capital asset prices: Theory and empirical evidence. Journal of Financial Economics 7, 163-195.

Ludvigson, S. C., Ng, S., 2009. Macro factors in bond risk premia. Review of Financial Studies 22, 5027-5067. 
Maio, P., Santa-Clara, P., 2012. Multifactor models and their consistency with the ICAPM. Journal of Financial Economics 106, 586-613.

Merton, R. C., 1973. An intertemporal capital asset pricing model. Econometrica 41, 867-887.

Moreira, A., Muir, T., 2017. Volatility-managed portfolios. Journal of Finance 72, 1611-1644.

Nagel, S., Singleton, K. J., 2011. Estimation and evaluation of conditional asset pricing models. Journal of Finance 66, 873-909.

Newey, W. K., West, K. D., 1987. A simple, positive semi-definite, heteroskedasticity and autocorrelation consistent covariance matrix. Econometrica 55, 703-708.

Novy-Marx, R., 2014. Predicting anomaly performance with politics, the weather, global warming, sunspots, and the stars. Journal of Financial Economics 112, 137-146.

Petkova, R., 2006. Do the Fama-French factors proxy for innovations in predictive variables? Journal of Finance 61, 581-612.

Restoy, F., Weil, P., 2010. Approximate equilibrium asset prices. Review of Finance 15, 1-28.

Roll, R., 1977. A critique of the asset pricing theory's tests; Part I: On past and potential testability of the theory. Journal of Financial Economics 4, 129-176.

Rossi, A. G., Timmermann, A., 2015. Modeling covariance risk in Merton's ICAPM. Review of Financial Studies 28, 1428-1461.

Scruggs, J. T., 1998. Resolving the puzzling intertemporal relation between the market risk premium and conditional market variance: A two-factor approach. Journal of Finance 53, 575-603.

Sundaresan, S. M., 1989. Intertemporally dependent preferences and the volatility of consumption and wealth. Review of Financial Studies 2, 73-89.

Vasicek, O. A., 1973. A note on using cross-sectional information in Bayesian estimation of security betas. Journal of Finance 28, 1233-1239.

Weil, P., 1989. The equity premium puzzle and the risk-free rate puzzle. Journal of Monetary Economics 24 , $401-421$. 

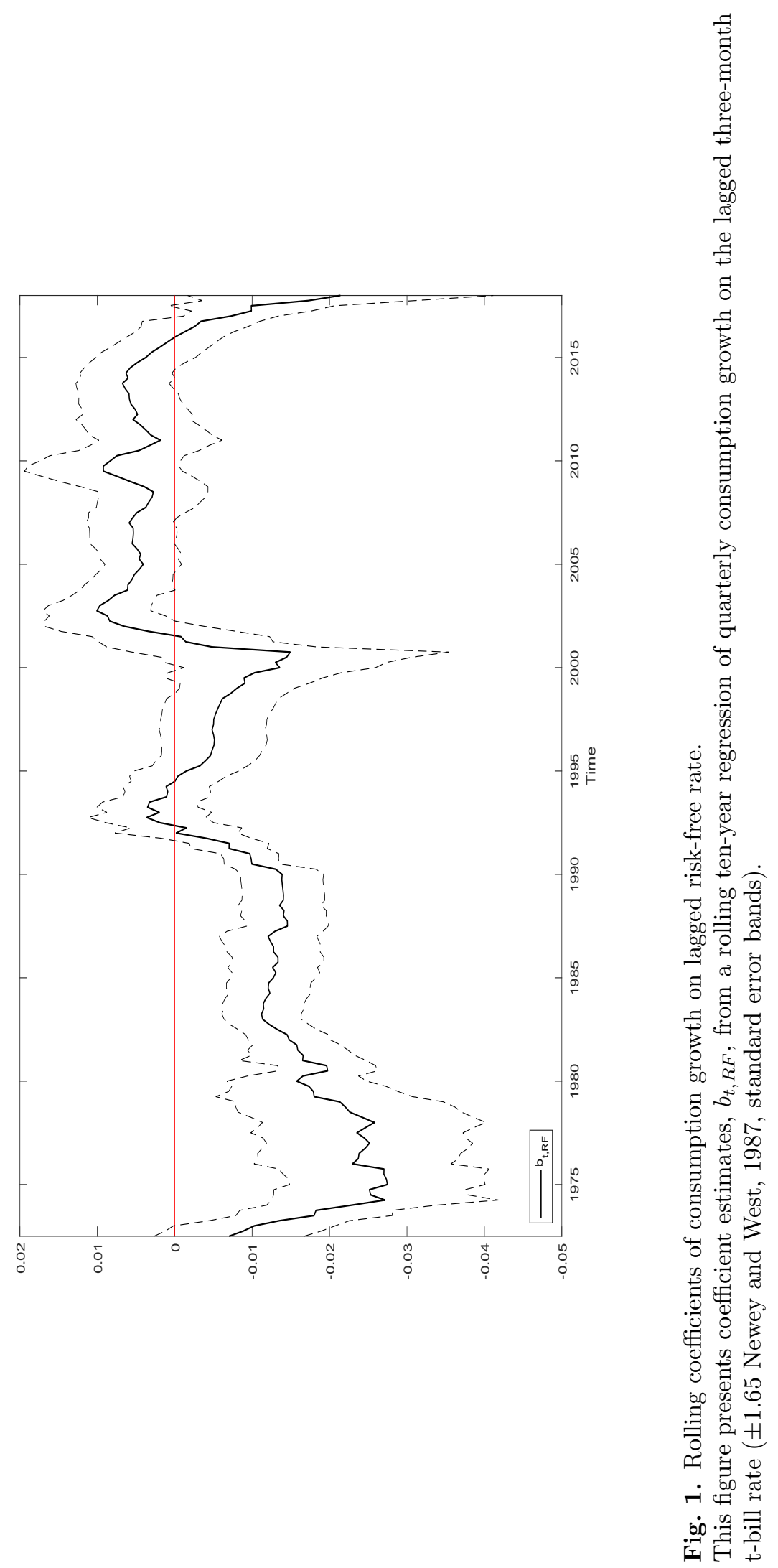

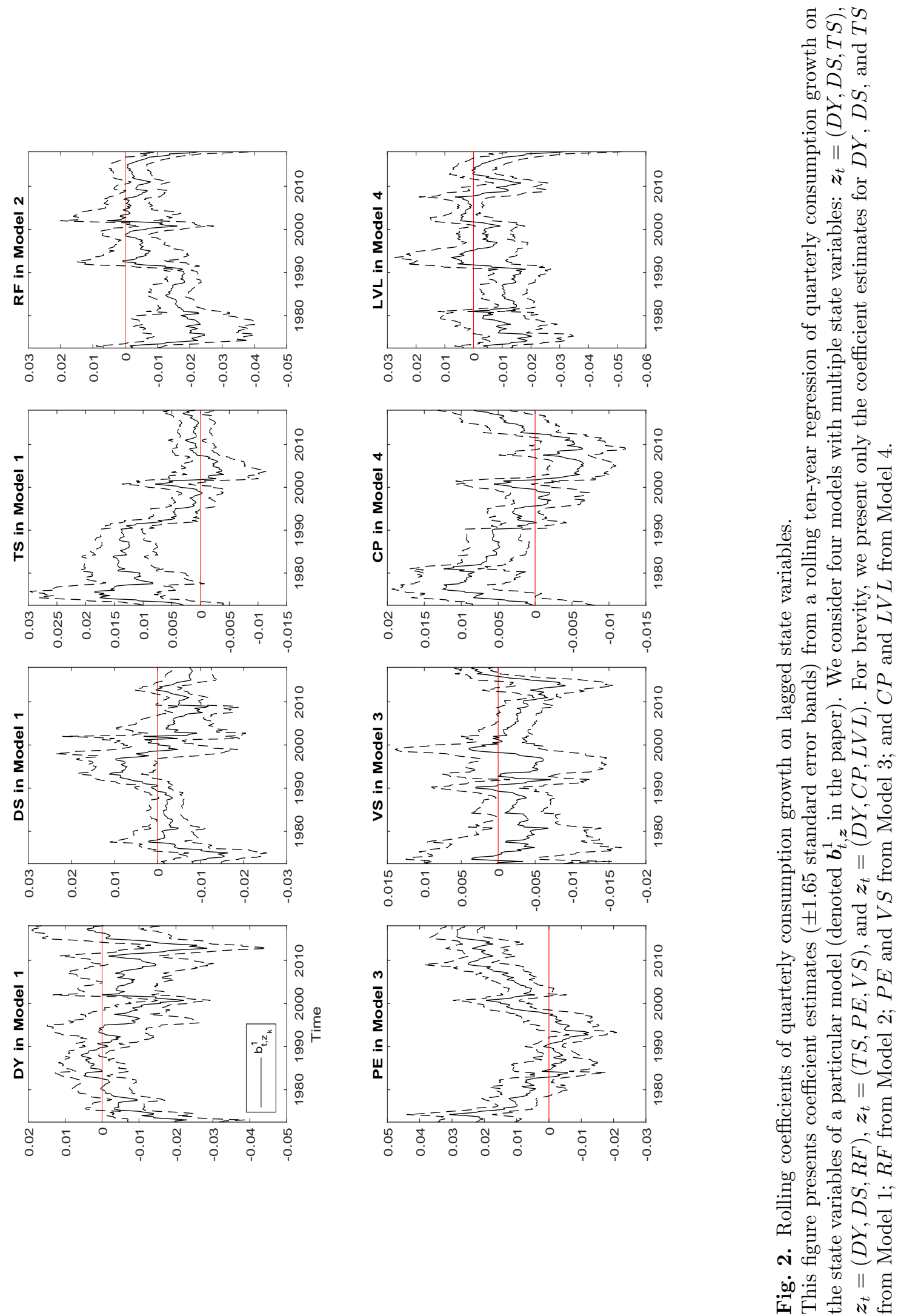

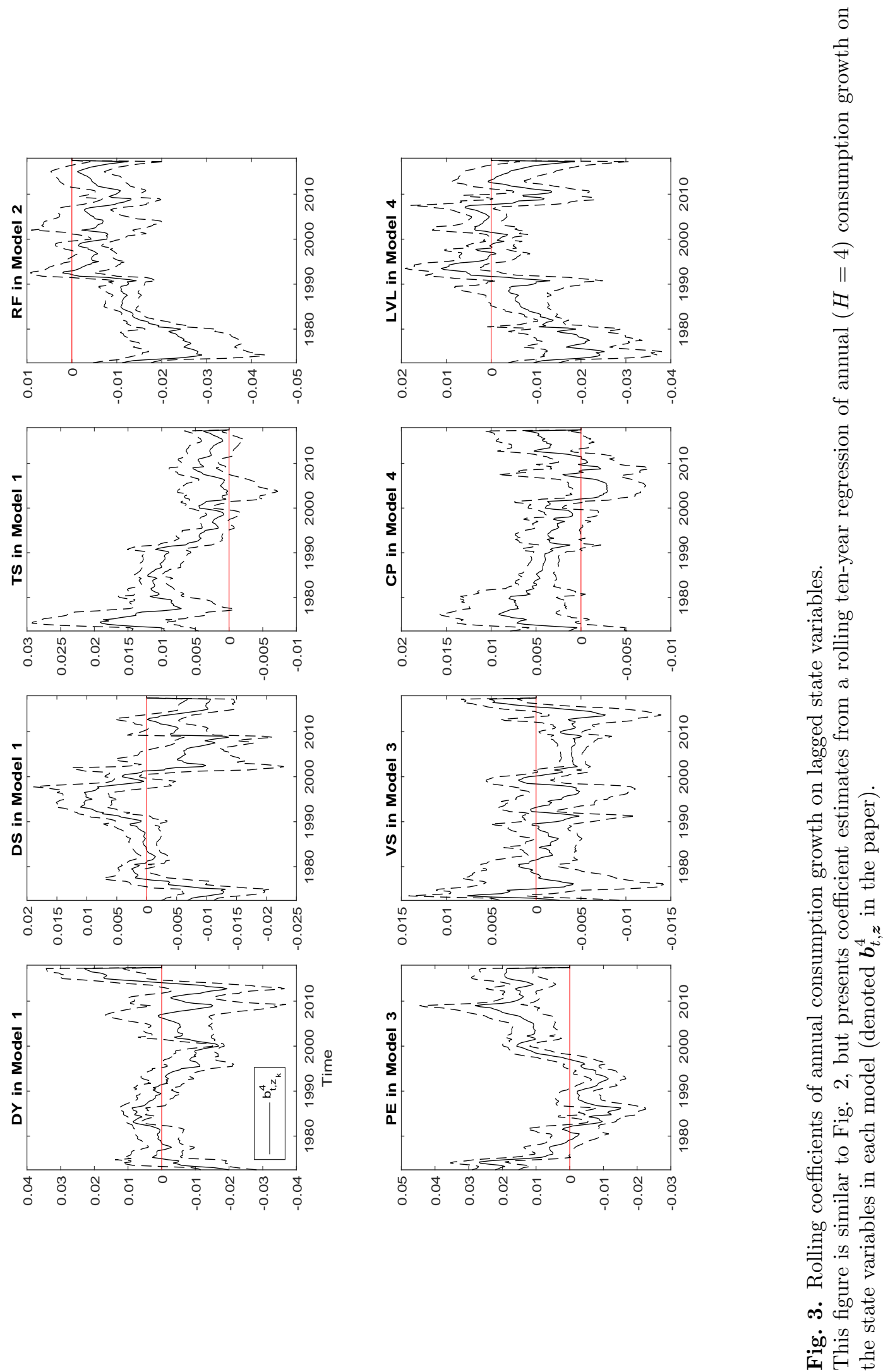


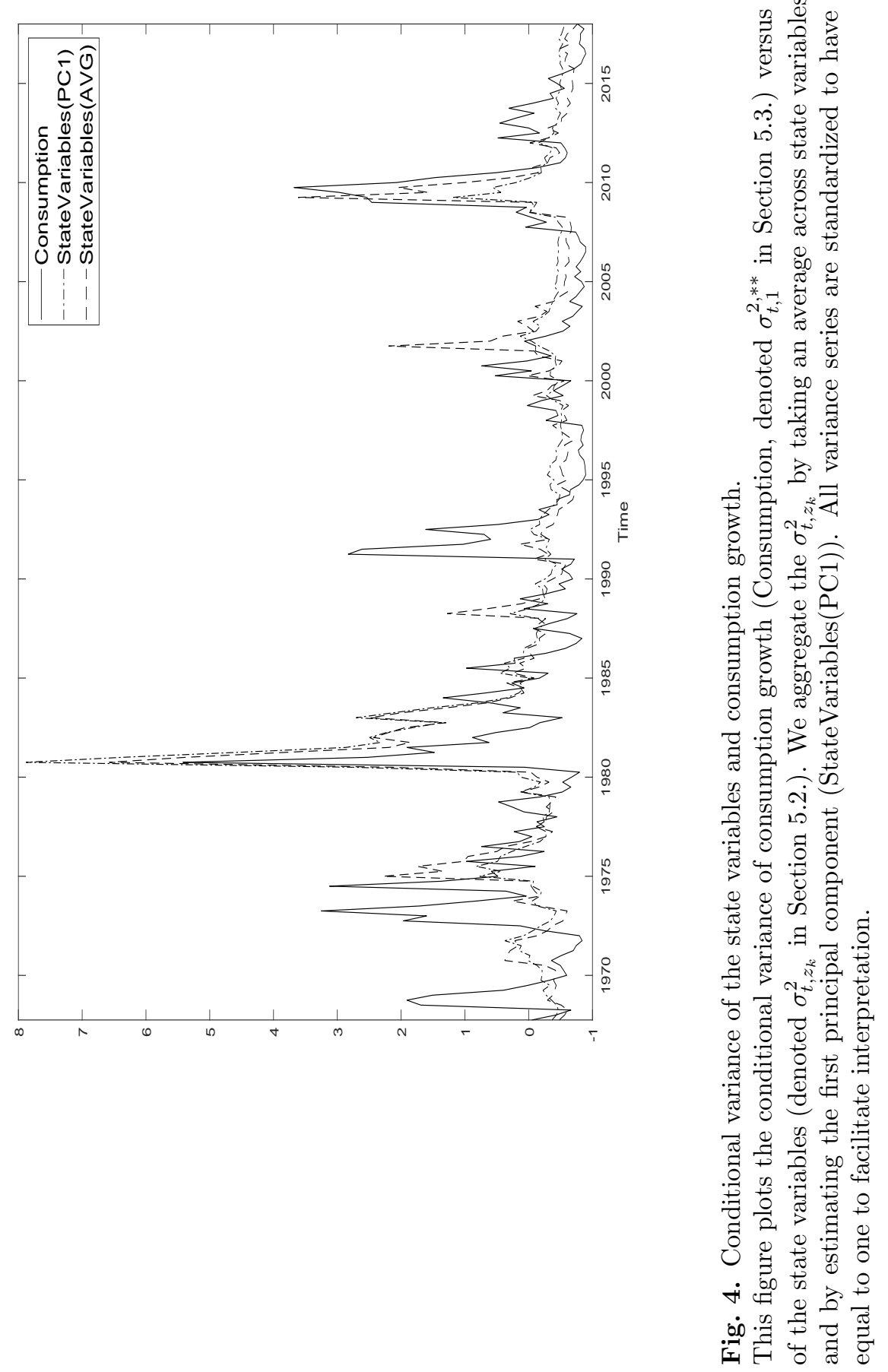


Table 1

Unconditional consumption growth predictability.

This table presents an unconditional regression of log consumption growth (cumulated over horizons $H=$ 1, 2, 4 quarters) on the lagged state variables, $\boldsymbol{z}_{t}$, from four different models: $c_{t+1: t+H}=a_{\boldsymbol{z}}^{H}+\boldsymbol{b}_{\boldsymbol{z}}^{H \prime} \boldsymbol{z}_{t}+e_{t+1: t+H}^{u}$. Model 1 sets $\boldsymbol{z}=(D Y, D S, T S)$, Model 2 sets $\boldsymbol{z}=(D Y, D S, R F)$, Model 3 sets $\boldsymbol{z}=(T S, P E, V S)$, and Model 4 sets $\boldsymbol{z}=(D Y, C P, L V L)$. The $t$-statistics using Newey and West (1987) standard errors with $H$ lags are presented in parentheses underneath each coefficient estimate. The sample period is the second quarter of 1962 to the fourth quarter of 2017.

\begin{tabular}{|c|c|c|c|c|c|c|c|}
\hline Horizon $H$ & 1 & 2 & 4 & & 1 & 2 & 4 \\
\hline \multicolumn{4}{|c|}{ Model 1} & \multicolumn{4}{|c|}{ Model 2} \\
\hline$D Y$ & $\begin{array}{c}0.38 \\
(2.38)\end{array}$ & $\begin{array}{c}0.42 \\
(2.56)\end{array}$ & $\begin{array}{c}0.45 \\
(2.35)\end{array}$ & $D Y$ & $\begin{array}{c}0.25 \\
(1.36)\end{array}$ & $\begin{array}{c}0.33 \\
(1.74)\end{array}$ & $\begin{array}{c}0.39 \\
(1.81)\end{array}$ \\
\hline$D S$ & $\begin{array}{c}-0.59 \\
(-3.51)\end{array}$ & $\begin{array}{c}-0.57 \\
(-3.16)\end{array}$ & $\begin{array}{c}-0.49 \\
(-2.53)\end{array}$ & $D S$ & $\begin{array}{c}-0.51 \\
(-3.01)\end{array}$ & $\begin{array}{c}-0.48 \\
(-2.60)\end{array}$ & $\begin{array}{l}-0.40 \\
(-1.98)\end{array}$ \\
\hline$T S$ & $\begin{array}{c}0.24 \\
(1.43)\end{array}$ & $\begin{array}{c}0.24 \\
(1.55)\end{array}$ & $\begin{array}{c}0.27 \\
(1.72)\end{array}$ & $R F$ & $\begin{array}{c}0.01 \\
(0.06)\end{array}$ & $\begin{array}{c}-0.03 \\
(-0.16)\end{array}$ & $\begin{array}{l}-0.10 \\
(-0.47)\end{array}$ \\
\hline$R^{2}(\times 100)$ & 7.11 & 9.38 & 10.25 & $R^{2}(\times 100)$ & 5.63 & 7.39 & 7.38 \\
\hline \multicolumn{4}{|c|}{ Model 3} & \multicolumn{4}{|c|}{ Model 4} \\
\hline$T S$ & $\begin{array}{c}0.06 \\
(0.36)\end{array}$ & $\begin{array}{c}0.05 \\
(0.31)\end{array}$ & $\begin{array}{c}0.07 \\
(0.41)\end{array}$ & $D Y$ & $\begin{array}{c}-0.11 \\
(-0.58)\end{array}$ & $\begin{array}{c}-0.02 \\
(-0.09)\end{array}$ & $\begin{array}{c}0.09 \\
(0.42)\end{array}$ \\
\hline$P E$ & $\begin{array}{c}0.12 \\
(0.77)\end{array}$ & $\begin{array}{c}0.06 \\
(0.39)\end{array}$ & $\begin{array}{c}-0.03 \\
(-0.14)\end{array}$ & $C P$ & $\begin{array}{c}0.27 \\
(1.42)\end{array}$ & $\begin{array}{c}0.26 \\
(1.64)\end{array}$ & $\begin{array}{c}0.28 \\
(2.10)\end{array}$ \\
\hline$V S$ & $\begin{array}{c}-0.21 \\
(-1.53)\end{array}$ & $\begin{array}{c}-0.17 \\
(-1.25)\end{array}$ & $\begin{array}{l}-0.07 \\
(-0.52)\end{array}$ & $L V L$ & $\begin{array}{c}0.19 \\
(0.86)\end{array}$ & $\begin{array}{c}0.15 \\
(0.61)\end{array}$ & $\begin{array}{c}0.07 \\
(0.28)\end{array}$ \\
\hline$R^{2}(\times 100)$ & -0.20 & -0.34 & -0.87 & $R^{2}(\times 100)$ & 2.01 & 2.83 & 4.88 \\
\hline
\end{tabular}




\section{Table 2}

Conditional consumption growth predictability.

This table presents the results from a two-stage test for time-varying consumption growth predictability. In the first stage, we regress consumption growth on the lagged state variables over a backward-looking rolling window of ten years (see Eq. (6) in the paper). In the second stage, we use the estimated rolling coefficients and the state variables observed at time $t$ to predict consumption growth from quarter $t+1$ to $t+H$ (see Eq. (7) in the paper). This setup ensures that we use no forward-looking information when we predict consumption growth in the second stage. We perform this test for each of the four models with $\boldsymbol{z}=(D Y, D S, T S)$; $\boldsymbol{z}=(D Y, D S, R F) ; \boldsymbol{z}=(T S, P E, V S)$; and, finally, $\boldsymbol{z}=(D Y, C P, L V L)$. We present $t$-statistics calculated using asymptotic Newey and West (1987, with $H$ lags) standard errors in parentheses and using standard errors derived from 1,000 block-bootstrapped coefficient estimates in brackets. We report three measures of fit (in percentage form, i.e., $\times 100$ ): the simple $R^{2}$, an $R^{2}$ comparison with the unconditional model of Table 1 (calculated as: $1-\operatorname{var}\left(e_{t+1: t+H}^{c}\right) / \operatorname{var}\left(e_{t+1: t+H}^{u}\right)$ ), and, finally, an $R^{2}$ comparison with a conditional model that leaves out the state variables (such that consumption growth is only conditioned on its historical mean). The sample in the second stage regression runs from the second quarter of 1967 to the fourth quarter of 2017.

\begin{tabular}{|c|c|c|c|c|c|c|}
\hline Horizon $H$ & 1 & 2 & 4 & 1 & 2 & 4 \\
\hline & \multicolumn{3}{|c|}{ Model 1} & \multicolumn{3}{|c|}{ Model 2} \\
\hline$d_{0}^{H}$ & $\begin{array}{c}0.01 \\
(3.56) \\
{[2.08]}\end{array}$ & $\begin{array}{c}0.01 \\
(4.58) \\
{[2.40]}\end{array}$ & $\begin{array}{c}0.01 \\
(4.20) \\
{[2.18]}\end{array}$ & $\begin{array}{c}0.01 \\
(4.76) \\
{[2.76]}\end{array}$ & $\begin{array}{l}0.01 \\
(6.19) \\
{[2.95]}\end{array}$ & $\begin{array}{c}0.01 \\
(6.11) \\
{[2.73]}\end{array}$ \\
\hline$d_{1}^{H}$ & $\begin{array}{c}0.63 \\
(7.29) \\
{[4.67]}\end{array}$ & $\begin{array}{c}0.51 \\
(6.13) \\
{[3.41]}\end{array}$ & $\begin{array}{l}0.45 \\
(5.53) \\
{[2.62]}\end{array}$ & $\begin{array}{c}0.58 \\
(6.77) \\
{[4.38]}\end{array}$ & $\begin{array}{l}0.49 \\
(6.71) \\
{[3.33]}\end{array}$ & $\begin{array}{l}0.43 \\
(6.48) \\
{[2.50]}\end{array}$ \\
\hline $\begin{array}{l}R^{2} \\
R^{2} \text { vs Unconditional } \\
R^{2} \text { vs Historical mean } \\
\end{array}$ & $\begin{array}{l}25.67 \\
21.71 \\
23.19 \\
\end{array}$ & $\begin{array}{l}24.80 \\
19.60 \\
22.00 \\
\end{array}$ & $\begin{array}{l}20.66 \\
14.14 \\
18.93 \\
\end{array}$ & $\begin{array}{l}22.41 \\
19.94 \\
19.81 \\
\end{array}$ & $\begin{array}{l}24.87 \\
21.97 \\
22.07 \\
\end{array}$ & $\begin{array}{l}22.79 \\
20.85 \\
21.11 \\
\end{array}$ \\
\hline$R^{2}$ vs Historical mean & \multicolumn{3}{|c|}{ Model 3} & \multicolumn{3}{|c|}{ Model 4} \\
\hline$d_{0}^{H}$ & $\begin{array}{l}0.01 \\
(2.67) \\
{[1.59]}\end{array}$ & $\begin{array}{l}0.01 \\
(2.65) \\
{[1.65]}\end{array}$ & $\begin{array}{l}0.01 \\
(3.18) \\
{[2.46]}\end{array}$ & $\begin{array}{l}0.01 \\
(3.23) \\
{[2.30]}\end{array}$ & $\begin{array}{l}0.01 \\
(3.98) \\
{[2.61]}\end{array}$ & $\begin{array}{c}0.01 \\
(4.29) \\
{[2.69]}\end{array}$ \\
\hline$d_{1}^{H}$ & $\begin{array}{l}0.71 \\
(7.79) \\
{[4.70]}\end{array}$ & $\begin{array}{l}0.65 \\
(6.53) \\
{[4.07]}\end{array}$ & $\begin{array}{c}0.45 \\
(3.42) \\
{[2.61]}\end{array}$ & $\begin{array}{l}0.56 \\
(5.32) \\
{[4.03]}\end{array}$ & $\begin{array}{c}0.48 \\
(4.58) \\
{[3.23]}\end{array}$ & $\begin{array}{c}0.37 \\
(3.43) \\
{[2.22]}\end{array}$ \\
\hline $\begin{array}{l}R^{2} \\
R^{2} \text { vs Unconditional } \\
R^{2} \text { vs Historical mean }\end{array}$ & $\begin{array}{l}26.80 \\
25.14 \\
24.35\end{array}$ & $\begin{array}{l}28.54 \\
26.58 \\
25.88\end{array}$ & $\begin{array}{l}17.32 \\
13.71 \\
15.52\end{array}$ & $\begin{array}{l}17.30 \\
10.86 \\
14.53\end{array}$ & $\begin{array}{c}15.73 \\
7.22 \\
12.60\end{array}$ & $\begin{array}{c}10.74 \\
-3.96 \\
8.81\end{array}$ \\
\hline
\end{tabular}




\section{Table 3}

State variable risk premia.

This table presents the unconditional state variable risk premia $\left(\boldsymbol{\lambda}_{t+1, \boldsymbol{z}}\right)$ in the four ICAPM specifications that we study. The state variable risk premia are annualized and estimated using Fama and MacBeth (1973) cross-sectional regressions of quarterly individual stock returns on lagged exposures to the innovations in the state variables. The sample period is from the second quarter of 1967 to the fourth quarter of 2017.

\begin{tabular}{|c|c|c|c|c|c|c|c|c|c|c|c|c|}
\hline & \multicolumn{3}{|c|}{ Model 1} & \multicolumn{3}{|c|}{ Model 2} & \multicolumn{3}{|c|}{ Model 3} & \multicolumn{3}{|c|}{ Model 4} \\
\hline & $D Y$ & $D S$ & $T S$ & $D Y$ & $D S$ & $R F$ & $T S$ & $P E$ & $V S$ & $D Y$ & $C P$ & $L V L$ \\
\hline Avg. Ret. & 0.90 & 0.17 & 4.51 & 0.33 & -1.08 & -3.95 & 1.94 & 0.24 & -4.43 & 0.40 & 2.72 & -3.66 \\
\hline$(t$-stat $)$ & $(0.43)$ & $(0.08)$ & $(2.14)$ & $(0.16)$ & $(-0.50)$ & $(-1.84)$ & $(0.94)$ & $(0.12)$ & $(-2.07)$ & $(0.20)$ & $(1.26)$ & $(-1.73)$ \\
\hline St. Dev. & 15.02 & 15.13 & 15.05 & 14.56 & 15.22 & 15.30 & 14.66 & 14.61 & 15.21 & 14.42 & 15.42 & 15.12 \\
\hline Sharpe & 0.06 & 0.01 & 0.30 & 0.02 & -0.07 & -0.26 & 0.13 & 0.02 & -0.29 & 0.03 & 0.18 & -0.24 \\
\hline
\end{tabular}




\section{Table 4}

Time-varying state variable risk premia.

In this table, we present the results from pooled predictive regressions of the state variable risk premia on the lagged relation between the state variables and consumption growth: $\lambda_{t+1: t+H, z_{k}}=g_{0}+g_{1} b_{t, z_{k}}^{H}+$ $\varepsilon_{t+1: t+H, z_{k}}$. Specifications 1 to 4 run the pooled regressions for eight state variables, which are: $\lambda_{t+1, D Y}$, $\lambda_{t+1, D S}$, and $\lambda_{t+1, T S}$ from Model $1 ; \lambda_{t+1, R F}$ from Model $2 ; \lambda_{t+1, P E}$ and $\lambda_{t+1, V S}$ from Model 3 ; and, $\lambda_{t+1, C P}$ and $\lambda_{t+1, L V L}$ from Model 4 . The regressions in columns headed " $\checkmark$ " include state variable fixed effects. Specification 1 uses a dummy variable that equals one when $b_{t, z_{k}}^{H}$ is positive: $I_{b_{t, z_{k}}^{H}}>0$. Specification 2 uses a dummy variable that equals one when $b_{t, z_{k}}^{H}$ is above the time-series median for a given state variable: $I_{b_{t, z_{k}}^{H}}>$ median. For this dummy, the coefficient estimate $g_{1}$ is identical with and without fixed effects, so we add the " $\checkmark$ " but report the estimated intercept from the model without fixed effects. Specifications 3 and 4 use the raw measure, $b_{t, z_{k}}^{H}$, as an independent variable. In specifications 5.1 to 5.4 we run the pooled regression with the dummy $I_{b_{t, z_{k}}^{H}}>$ median for the three state variables in each model: $\boldsymbol{z}=(D Y, D S, T S)$ in Model $1, \boldsymbol{z}=(D Y, D S, R F)$ in Model 2, $\boldsymbol{z}=(T S, P E, V S)$ in Model 3, and $\boldsymbol{z}=(D Y, C P, L V L)$ in Model 4. The $t$-statistic in parentheses underneath each estimate is based on asymptotic Driscoll and Kraay (1998) standard errors; the $t$-statistic in brackets is based on standard errors derived from 1,000 block-bootstrapped coefficient estimates. The sample period is the second quarter of 1967 to the fourth quarter of 2017.

\begin{tabular}{|c|c|c|c|c|c|c|c|c|}
\hline $\begin{array}{l}\text { Specification } \\
\text { Fixed effects }\end{array}$ & 1 & $\begin{array}{l}2 \\
\checkmark\end{array}$ & 3 & $\begin{array}{l}4 \\
\checkmark\end{array}$ & $\begin{array}{l}5.1 \\
\checkmark\end{array}$ & $\begin{array}{l}5.2 \\
\checkmark\end{array}$ & $\begin{array}{l}5.3 \\
\checkmark\end{array}$ & $\begin{array}{l}5.4 \\
\checkmark\end{array}$ \\
\hline \multicolumn{9}{|c|}{ Panel A: Quarterly returns $(H=1)$} \\
\hline$g_{0}$ & $\begin{array}{c}-2.04 \\
(-1.92) \\
{[-1.66]}\end{array}$ & $\begin{array}{c}-3.04 \\
(-2.52) \\
{[-2.38]}\end{array}$ & $\begin{array}{l}-0.22 \\
(-0.39) \\
{[-0.32]}\end{array}$ & & $\begin{array}{c}-1.44 \\
(-0.84) \\
{[-0.68]}\end{array}$ & $\begin{array}{c}-4.51 \\
(-1.95) \\
{[-2.20]}\end{array}$ & $\begin{array}{c}-1.86 \\
(-1.40) \\
{[-0.95]}\end{array}$ & $\begin{array}{l}-1.85 \\
(-1.04) \\
{[-0.92]}\end{array}$ \\
\hline$I_{b_{t, z_{k}}^{1}}>0$ & $\begin{array}{c}3.93 \\
(1.63) \\
{[1.86]}\end{array}$ & & & & & & & \\
\hline \multirow{2}{*}{$I_{b_{t, z_{k}}^{1}}>$ median } & & 5.17 & & & 6.89 & 6.17 & 1.91 & 3.23 \\
\hline & & $\begin{array}{l}(2.25) \\
{[2.34]}\end{array}$ & & & $\begin{array}{l}(2.45) \\
{[2.22]}\end{array}$ & $\begin{array}{l}(2.10) \\
{[2.00]}\end{array}$ & $\begin{array}{l}(0.81) \\
{[0.69]}\end{array}$ & $\begin{array}{l}(1.24) \\
{[1.10]}\end{array}$ \\
\hline$b_{t, z_{k}}^{1}$ & & & $\begin{array}{l}244.91 \\
(1.81) \\
{[2.15]}\end{array}$ & $\begin{array}{c}242.76 \\
(1.73) \\
{[1.88]}\end{array}$ & & & & \\
\hline$R^{2}(\times 100)$ & 0.41 & 1.77 & 0.66 & 1.41 & 1.68 & 1.45 & 0.92 & 1.01 \\
\hline \multicolumn{9}{|c|}{ Panel B: Semi-annual returns $(H=2)$} \\
\hline$g_{0}$ & $\begin{array}{c}-2.62 \\
(-2.61) \\
{[-2.10]}\end{array}$ & $\begin{array}{c}-2.91 \\
(-2.49) \\
{[-2.33]}\end{array}$ & $\begin{array}{c}0.01 \\
(0.01) \\
{[0.01]}\end{array}$ & & $\begin{array}{c}-0.90 \\
(-0.58) \\
{[-0.43]}\end{array}$ & $\begin{array}{c}-3.40 \\
(-1.62) \\
{[-1.71]}\end{array}$ & $\begin{array}{c}-1.82 \\
(-1.33) \\
{[-0.91]}\end{array}$ & $\begin{array}{l}-3.01 \\
(-1.90) \\
{[-1.56]}\end{array}$ \\
\hline$I_{b_{t, z_{k}}^{2}}>0$ & $\begin{array}{c}5.61 \\
(2.41) \\
{[2.64]}\end{array}$ & & & & & & & \\
\hline \multirow{2}{*}{$I_{b_{t, z_{k}}^{2}}>$ median } & & 5.16 & & & 6.30 & 4.36 & 1.88 & 5.59 \\
\hline & & $\begin{array}{l}(2.32) \\
{[2.43]}\end{array}$ & & & $\begin{array}{l}(2.27) \\
{[2.08]}\end{array}$ & $\begin{array}{l}(1.65) \\
{[1.43]}\end{array}$ & $\begin{array}{l}(0.81) \\
{[0.69]}\end{array}$ & $\begin{array}{l}(2.41) \\
{[2.00]}\end{array}$ \\
\hline$b_{t, z_{k}}^{2}$ & & & $\begin{array}{l}308.82 \\
(2.15) \\
{[2.56]}\end{array}$ & $\begin{array}{c}297.54 \\
(2.05) \\
{[2.13]}\end{array}$ & & & & \\
\hline \multirow[t]{2}{*}{$R^{2}(\times 100)$} & 1.44 & 3.19 & 1.64 & 2.84 & 2.69 & 1.74 & 1.60 & 2.79 \\
\hline & & Pan & C: Ann & al return & $(H=4)$ & & & \\
\hline$g_{0}$ & $\begin{array}{c}-3.32 \\
(-2.80) \\
{[-2.46]}\end{array}$ & $\begin{array}{c}-3.39 \\
(-3.00) \\
{[-2.66]}\end{array}$ & $\begin{array}{c}0.06 \\
(0.10) \\
{[0.08]}\end{array}$ & & $\begin{array}{c}-1.49 \\
(-1.07) \\
{[-0.71]}\end{array}$ & $\begin{array}{c}-3.00 \\
(-1.40) \\
{[-1.50]}\end{array}$ & $\begin{array}{c}-2.75 \\
(-2.17) \\
{[-1.35]}\end{array}$ & $\begin{array}{l}-3.29 \\
(-2.34) \\
{[-1.70]}\end{array}$ \\
\hline$I_{b_{t, z_{k}}^{4}}>0$ & $\begin{array}{c}6.51 \\
(2.54) \\
{[2.87]}\end{array}$ & & & & & & & \\
\hline \multirow[t]{2}{*}{$I_{b_{t, z_{k}}^{4}}>$ median } & & 6.31 & & & 7.63 & 3.89 & 3.78 & 6.20 \\
\hline & & $\begin{array}{l}(2.87) \\
{[3.01]}\end{array}$ & & & $\begin{array}{l}(2.76) \\
{[2.60]}\end{array}$ & $\begin{array}{l}(1.51) \\
{[1.30]}\end{array}$ & $\begin{array}{l}(1.57) \\
{[1.37]}\end{array}$ & $\begin{array}{l}(2.78) \\
{[2.18]}\end{array}$ \\
\hline$b_{t, z_{k}}^{4}$ & & & $\begin{array}{l}321.64 \\
(2.14) \\
{[2.64]}\end{array}$ & $\begin{array}{r}297.70 \\
4(\mathrm{~b} .13) \\
{[2.10]}\end{array}$ & & & & \\
\hline$R^{2}(\times 100)$ & 3.37 & 6.37 & 3.02 & 4.78 & 6.24 & 2.79 & 3.30 & 5.16 \\
\hline
\end{tabular}




\section{Table 5}

Conditional variance of state variables and risk premia.

Panel A of this table presents coefficient estimates for the annual horizon $(H=4)$ from pooled predictive regressions of state variable risk premia on the conditional relation between each state variable and future consumption growth interacted with the $\operatorname{GARCH}(1,1)$ conditional variance of the state variables: $\lambda_{t+1: t+4, z_{k}}=g_{0}+g_{1} b_{t, z_{k}}+g_{2} \sigma_{t, z_{k}}^{2}+g_{3} \sigma_{t, z_{k}}^{2} \times b_{t, z_{k}}+\varepsilon_{t+1: t+4, z_{k}}$. Conditional variance, $\sigma_{t, z_{k}}^{2}$, is standardized to have mean equal to zero and variance equal to one for each state variable $z_{k}$. The dependent variables are the risk premia for the eight state variables of interest (i.e., $\lambda_{t+1, D Y}, \lambda_{t+1, D S}$, and $\lambda_{t+1, T S}$ from Model 1; $\lambda_{t+1, R F}$ from Model $2 ; \lambda_{t+1, P E}$ and $\lambda_{t+1, V S}$ from Model 3; and $\lambda_{t+1, C P}$ and $\lambda_{t+1, L V L}$ from Model 4). In the right column, we estimate a dummy specification, replacing $b_{t, z_{k}}$ with the indicator $I_{b_{t, z_{k}}>0}$ and $\sigma_{t, z_{k}}^{2}$ with the indicator $I_{\sigma_{t, z_{k}}^{2}}>$ median. To grasp the economic significance of the estimates, in Panel B we present the predicted risk premium in quarters with $b_{t, z_{k}}$ one standard deviation below or above the mean versus $\sigma_{t, z_{k}}^{2}$ at the mean or one standard deviation above the mean. For the dummy specification, we present the implied risk premium in quarters with positive or negative $b_{t, z_{k}}$ and conditional variance below or above median. $H H-L H$ presents the difference between case one and four. The $t$-statistic in parentheses underneath each estimate is based on asymptotic Driscoll and Kraay (1998) standard errors; the $t$-statistic in brackets is based on standard errors derived from 1,000 block-bootstrapped coefficient estimates.

\begin{tabular}{|c|c|c|c|c|c|}
\hline \multicolumn{3}{|c|}{ Continuous: $b_{t, z_{k}}$ and $\sigma_{t, z_{k}}^{2}$} & \multicolumn{3}{|c|}{ Dummy: $I_{b_{t, z_{k}}>0}$ and $I_{\sigma_{t, z_{k}}^{2}}>$ median } \\
\hline Fixed effects & & $\checkmark$ & & & $\checkmark$ \\
\hline \multicolumn{6}{|c|}{ Panel A: Coefficient estimates } \\
\hline$g_{0}$ & $\begin{array}{c}0.00 \\
(0.00)\end{array}$ & & $g_{0}$ & $\begin{array}{l}-1.91 \\
(-2.05)\end{array}$ & \\
\hline$b_{t, z_{k}}$ & $\begin{array}{l}270.68 \\
(1.95)\end{array}$ & $\begin{array}{c}252.42 \\
(1.91)\end{array}$ & $I_{b_{t, z_{k}}}>0$ & $\begin{array}{c}2.39 \\
(1.56)\end{array}$ & $\begin{array}{c}0.90 \\
(0.46)\end{array}$ \\
\hline$\sigma_{t, z_{k}}^{2}$ & $\begin{array}{c}0.56 \\
(0.54)\end{array}$ & $\begin{array}{c}0.56 \\
(0.58)\end{array}$ & $I_{\sigma_{t, z_{k}}^{2}}>$ median & $\begin{array}{c}-2.98 \\
(-1.52)\end{array}$ & $\begin{array}{l}-2.77 \\
(-1.43)\end{array}$ \\
\hline$b_{t, z_{k}} \times \sigma_{t, z_{k}}^{2}$ & $\begin{array}{c}185.86 \\
(1.95)\end{array}$ & $\begin{array}{l}185.91 \\
(2.00)\end{array}$ & $I_{b_{t, z_{k}}>0} \times I_{\sigma_{t, z_{k}}^{2}>\text { median }}$ & $\begin{array}{c}8.09 \\
(1.98)\end{array}$ & $\begin{array}{c}7.84 \\
(1.91)\end{array}$ \\
\hline$R^{2}(\times 100)$ & 5.00 & 6.75 & $R^{2}(\times 100)$ & 4.72 & 5.67 \\
\hline \multicolumn{6}{|c|}{ Panel B: Predicted state variable risk premia } \\
\hline Low $b_{t, z_{k}}$, High $\sigma_{t, z_{k}}^{2}$ & $\begin{array}{c}-4.36 \\
(-2.64) \\
{[-2.36]}\end{array}$ & $\begin{array}{l}-4.19 \\
(-2.42) \\
{[-2.11]}\end{array}$ & & $\begin{array}{c}-4.89 \\
(-2.47) \\
{[-2.81]}\end{array}$ & $\begin{array}{l}-4.02 \\
(-2.36) \\
{[-2.23]}\end{array}$ \\
\hline Low $b_{t, z_{k}}$, Low $\sigma_{t, z_{k}}^{2}$ & $\begin{array}{c}-2.90 \\
(-2.13) \\
{[-2.14]}\end{array}$ & $\begin{array}{l}-2.73 \\
(-1.96) \\
{[-1.77]}\end{array}$ & & $\begin{array}{c}-1.91 \\
(-2.05) \\
{[-1.15]}\end{array}$ & $\begin{array}{l}-1.25 \\
(-1.11) \\
{[-0.71]}\end{array}$ \\
\hline High $b_{t, z_{k}}$, Low $\sigma_{t, z_{k}}^{2}$ & $\begin{array}{c}2.44 \\
(1.62) \\
{[1.69]}\end{array}$ & $\begin{array}{c}2.27 \\
(1.67) \\
{[1.42]}\end{array}$ & & $\begin{array}{c}0.48 \\
(0.46) \\
{[0.29]}\end{array}$ & $\begin{array}{l}-0.34 \\
(-0.29) \\
{[-0.20]}\end{array}$ \\
\hline High $b_{t, z_{k}}$, High $\sigma_{t, z_{k}}^{2}$ & $\begin{array}{c}4.73 \\
(1.93) \\
{[2.28]}\end{array}$ & $\begin{array}{c}4.56 \\
(2.12) \\
{[2.05]}\end{array}$ & & $\begin{array}{c}5.59 \\
(2.29) \\
{[3.10]}\end{array}$ & $\begin{array}{c}4.72 \\
(2.35) \\
{[2.52]}\end{array}$ \\
\hline$H H-L H$ & $\begin{array}{c}9.09 \\
(2.86) \\
{[2.85]}\end{array}$ & $\begin{array}{l}8.74 \\
(3.01) \\
{[2.47]}\end{array}$ & & $\begin{array}{l}10.49 \\
(2.51) \\
{[3.64]}\end{array}$ & $\begin{array}{l}8.74 \\
(2.58) \\
{[2.88]}\end{array}$ \\
\hline
\end{tabular}




\section{Table 6}

Macro-uncertainty and state variable risk premia.

The coefficient estimates in this table are from a pooled regression specification (at the annual horizon, $H=4$ ) that is similar to Table 5 , except that we now control for macro-uncertainty instead of the conditional variance of the state variables: $\lambda_{t+1: t+4, z_{k}}=g_{0}+g_{1} I_{b_{t, z_{k}}>0}+g_{2} I_{\sigma_{t}^{2}>\text { median }}+g_{3} I_{\sigma_{t}^{2}>\text { median }} \times I_{b_{t, z_{k}}>0}+$ $\varepsilon_{t+1: t+4, z_{k}}$. Here, the dummy $I_{\sigma_{t}^{2}>\text { median }}$ is defined using one of two macro-uncertainty measures described in Section 5.3.: $\sigma_{t}^{2, *}$ (the $\operatorname{GARCH}(1,1)$ conditional variance of consumption growth controlling for consumption predictability due to the state variables) and $\sigma_{t}^{2, * *}$ (the $\operatorname{GARCH}(1,1)$ conditional variance of demeaned consumption growth). The $t$-statistic in parentheses underneath each estimate is based on asymptotic Driscoll and Kraay (1998) standard errors; the $t$-statistic in brackets is based on standard errors derived from 1,000 block-bootstrapped coefficient estimates.

\begin{tabular}{|c|c|c|}
\hline Dummy: $I_{b_{t, z_{k}}>0}$ and & $I_{\sigma_{t}^{2, *}>\text { median }}$ & $I_{\sigma_{t}^{2, * *}>\text { median }}$ \\
\hline \multicolumn{3}{|c|}{ Panel A: Coefficient estimates } \\
\hline$g_{0}$ & $\begin{array}{c}-1.79 \\
(-1.30)\end{array}$ & $\begin{array}{c}-1.83 \\
(-1.46)\end{array}$ \\
\hline$I_{b_{t, z_{k}}>0}$ & $\begin{array}{c}3.64 \\
(1.39)\end{array}$ & $\begin{array}{c}3.72 \\
(1.56)\end{array}$ \\
\hline$I_{\sigma_{t}^{2}>\text { median }}$ & $\begin{array}{c}-3.07 \\
(-1.98)\end{array}$ & $\begin{array}{c}-2.97 \\
(-1.98)\end{array}$ \\
\hline$I_{b_{t, z_{k}}>0} \times I_{\sigma_{t}^{2}>\text { median }}$ & $\begin{array}{c}5.74 \\
(1.92)\end{array}$ & $\begin{array}{c}5.58 \\
(1.59)\end{array}$ \\
\hline$R^{2}(\times 100)$ & 4.03 & 4.00 \\
\hline \multicolumn{3}{|c|}{ Panel B: Predicted state variable risk premia } \\
\hline Low $b_{t, z_{k}}$, High $\sigma_{t}^{2}$ & $\begin{array}{c}-4.87 \\
(-3.52) \\
{[-2.70]}\end{array}$ & $\begin{array}{c}-4.81 \\
(-3.29) \\
{[-2.65]}\end{array}$ \\
\hline Low $b_{t, z_{k}}$, Low $\sigma_{t}^{2}$ & $\begin{array}{c}-1.79 \\
(-1.30) \\
{[-1.22]}\end{array}$ & $\begin{array}{c}-1.83 \\
(-1.46) \\
{[-1.24]}\end{array}$ \\
\hline High $b_{t, z_{k}}$, Low $\sigma_{t}^{2}$ & $\begin{array}{l}1.85 \\
(1.22) \\
{[1.20]}\end{array}$ & $\begin{array}{l}1.89 \\
(1.39) \\
{[1.23]}\end{array}$ \\
\hline $\operatorname{High} b_{t, z_{k}}$, High $\sigma_{t}^{2}$ & $\begin{array}{l}4.51 \\
(2.11) \\
{[2.45]}\end{array}$ & $\begin{array}{c}4.50 \\
(1.91) \\
{[2.39]}\end{array}$ \\
\hline$H H-L H$ & $\begin{array}{c}9.38 \\
(2.97) \\
{[3.03]} \\
\end{array}$ & $\begin{array}{c}9.30 \\
(2.60) \\
{[2.98]} \\
\end{array}$ \\
\hline
\end{tabular}




\section{Table 7}

Conditional variance of state variables net of macro-uncertainty.

This table is similar to Table 5, but controls for quarters when macro-uncertainty is high. To do so, we set the dummy capturing periods of high conditional variance of a state variable $z_{k}, I_{\sigma_{t, z_{k}}^{2}}>$ median , to zero in quarters when the conditional variance of consumption growth, $\sigma_{t, H}^{2, *}$ (or, analogously, $\sigma_{t, H}^{2, * *}$ ), is above median. We present predicted risk premia (at the annual horizon, $H=4$ ) estimated from a pooled regression of state variable risk premia on the dummy variable indicating whether the conditional relation between each state variable and future consumption growth is positive $\left(I_{b_{t, z_{k}}>0}\right)$ as well as the macro-uncertainty-adjusted dummy for the conditional variance of the state variables $\left(I_{\sigma_{t, z_{k}}^{2}}^{2}>\right.$ median $)$. The predicted risk premia are for the four cases also analyzed in Table 5 . The $t$-statistic in parentheses underneath each estimate is based on asymptotic Driscoll and Kraay (1998) standard errors. In the first column, we report results for the unadjusted dummy, $I_{\sigma_{t, z_{k}}^{2}}>$ median , for the sake of comparison.

\begin{tabular}{|c|c|c|c|}
\hline & $\begin{array}{l}\text { Unadjusted: } \\
I_{\sigma_{t, z_{k}}^{2}}>\text { median }\end{array}$ & $\begin{array}{l}\text { Adjusted: } I_{\sigma_{t, z_{k}}^{2}} \\
\sigma_{t}^{2, *}>\text { median }\end{array}$ & $\begin{array}{l}>\text { median }=0 \text { when } \\
\sigma_{t}^{2, * *}>\text { median }\end{array}$ \\
\hline \multicolumn{4}{|c|}{ Panel A: Coefficient estimates } \\
\hline$g_{0}$ & $\begin{array}{l}-1.91 \\
(-2.05)\end{array}$ & $\begin{array}{l}-3.25 \\
(-2.87)\end{array}$ & $\begin{array}{l}-3.23 \\
(-2.83)\end{array}$ \\
\hline$I_{b_{t, z_{k}}}>0$ & $\begin{array}{c}2.39 \\
(1.56)\end{array}$ & $\begin{array}{c}6.26 \\
(2.63)\end{array}$ & $\begin{array}{c}6.21 \\
(2.41)\end{array}$ \\
\hline$I_{\sigma_{t, z_{k}}^{2}}>$ median & $\begin{array}{c}-2.98 \\
(-1.52)\end{array}$ & $\begin{array}{c}-0.32 \\
(-0.13)\end{array}$ & $\begin{array}{l}-0.45 \\
(-0.21)\end{array}$ \\
\hline$I_{b_{t, z_{k}}>0} \times I_{\sigma_{t, z_{k}}^{2}}>$ median & $\begin{array}{c}8.09 \\
(1.98)\end{array}$ & $\begin{array}{c}1.14 \\
(0.26)\end{array}$ & $\begin{array}{c}1.40 \\
(0.35)\end{array}$ \\
\hline$R^{2}(\times 100)$ & 4.72 & 3.39 & 3.40 \\
\hline \multicolumn{4}{|c|}{ Panel B: Predicted state variable risk premia } \\
\hline Low $b_{t, z_{k}}$, High $\sigma_{t, z_{k}}^{2}$ & $\begin{array}{l}-4.89 \\
(-2.47)\end{array}$ & $\begin{array}{l}-3.58 \\
(-1.40)\end{array}$ & $\begin{array}{l}-3.68 \\
(-1.59)\end{array}$ \\
\hline Low $b_{t, z_{k}}$, Low $\sigma_{t, z_{k}}^{2}$ & $\begin{array}{l}-1.91 \\
(-2.05)\end{array}$ & $\begin{array}{l}-3.25 \\
(-2.87)\end{array}$ & $\begin{array}{l}-3.23 \\
(-2.83)\end{array}$ \\
\hline High $b_{t, z_{k}}$, Low $\sigma_{t, z_{k}}^{2}$ & $\begin{array}{c}0.48 \\
(0.46)\end{array}$ & $\begin{array}{c}3.01 \\
(1.94)\end{array}$ & $\begin{array}{c}2.97 \\
(1.79)\end{array}$ \\
\hline $\operatorname{High} b_{t, z_{k}}, \operatorname{High} \sigma_{t, z_{k}}^{2}$ & $\begin{array}{c}5.59 \\
(2.29)\end{array}$ & $\begin{array}{c}3.83 \\
(1.38)\end{array}$ & $\begin{array}{c}3.93 \\
(1.71)\end{array}$ \\
\hline$H H-L H$ & $\begin{array}{l}10.49 \\
(2.51) \\
\end{array}$ & $\begin{array}{c}7.41 \\
(1.49) \\
\end{array}$ & $\begin{array}{c}7.61 \\
(1.75) \\
\end{array}$ \\
\hline
\end{tabular}




\section{Table 8}

Time-varying risk premia controlling for benchmark factors.

This table presents results from the pooled predictive regressions of Table 5 (focusing on the annual horizon, $H=4$ ) controlling for unconditional exposure to the benchmark asset pricing factors of the CAPM, Fama-French three-factor model (FF3M), Carhart four-factor model (FFCM) and Fama-French five-factor model (FF5M). We run these pooled regressions for the High-minus-Low state variable risk premia that come from a sort of individual stocks into equal- and value-weighted quintiles. We report the predicted risk premia in the four cases that analyze the joint effect of variation in the conditional relation between the state variables and consumption growth and the $\operatorname{GARCH}(1,1)$ conditional variance of the state variables (plus their interaction term). We consider both the continuous specification (using $b_{t, z_{k}}$ and $\sigma_{t, z_{k}}^{2}$ ) and the dummy specification (using $I_{b_{t, z_{k}}>0}$ and $I_{\sigma_{t, z_{k}}^{2}}>$ median $)$. In both panels, the bottom row presents the fraction of the original effect (i.e., without controlling for the benchmark factors, reported in the first and sixth column) that remains after controlling for exposures in a particular factor model. The $t$-statistics in parenthesis are based on Driscoll and Kraay (1998) standard errors.

\begin{tabular}{|c|c|c|c|c|c|c|c|c|c|c|}
\hline & \multicolumn{5}{|c|}{ Equal-weighted } & \multicolumn{5}{|c|}{ Value-weighted } \\
\hline & No controls & CAPM & FF3M & FFCM & FF5M & No controls & CAPM & FF3M & FFCM & FF5M \\
\hline \multicolumn{11}{|c|}{ Panel A: Continuous specification with $b_{t, z_{k}}$ and $\sigma_{t, z_{k}}^{2}$} \\
\hline Low $b_{t, z_{k}}$, High $\sigma_{t, z_{k}}^{2}$ & $\begin{array}{c}-3.40 \\
(-2.21)\end{array}$ & $\begin{array}{c}-4.38 \\
(-2.86)\end{array}$ & $\begin{array}{l}-1.95 \\
(-1.55)\end{array}$ & $\begin{array}{l}-2.58 \\
(-2.03)\end{array}$ & $\begin{array}{c}-0.31 \\
(-0.28)\end{array}$ & $\begin{array}{l}-2.13 \\
(-1.50)\end{array}$ & $\begin{array}{c}-3.28 \\
(-2.31)\end{array}$ & $\begin{array}{c}-1.24 \\
(-0.97)\end{array}$ & $\begin{array}{l}-1.83 \\
(-1.44)\end{array}$ & $\begin{array}{c}0.13 \\
(0.11)\end{array}$ \\
\hline Low $b_{t, z_{k}}$, Low $\sigma_{t, z_{k}}^{2}$ & $\begin{array}{c}-2.83 \\
(-2.32)\end{array}$ & $\begin{array}{c}-3.77 \\
(-3.06)\end{array}$ & $\begin{array}{l}-1.52 \\
(-1.46)\end{array}$ & $\begin{array}{l}-2.29 \\
(-1.98)\end{array}$ & $\begin{array}{c}0.11 \\
(0.12)\end{array}$ & $\begin{array}{l}-1.35 \\
(-1.09)\end{array}$ & $\begin{array}{c}-2.46 \\
(-2.06)\end{array}$ & $\begin{array}{c}-0.64 \\
(-0.59)\end{array}$ & $\begin{array}{l}-1.34 \\
(-1.16)\end{array}$ & $\begin{array}{c}0.66 \\
(0.64)\end{array}$ \\
\hline $\operatorname{High} b_{t, z_{k}}$, Low $\sigma_{t, z_{k}}^{2}$ & $\begin{array}{c}1.95 \\
(1.50)\end{array}$ & $\begin{array}{c}1.58 \\
(1.13)\end{array}$ & $\begin{array}{l}-0.14 \\
(-0.11)\end{array}$ & $\begin{array}{l}-0.69 \\
(-0.69)\end{array}$ & $\begin{array}{c}-0.55 \\
(-0.47)\end{array}$ & $\begin{array}{c}2.58 \\
(2.22)\end{array}$ & $\begin{array}{c}1.86 \\
(1.55)\end{array}$ & $\begin{array}{c}1.06 \\
(0.82)\end{array}$ & $\begin{array}{c}0.41 \\
(0.43)\end{array}$ & $\begin{array}{c}1.20 \\
(0.87)\end{array}$ \\
\hline High $b_{t, z_{k}}$, High $\sigma_{t, z_{k}}^{2}$ & $\begin{array}{c}3.80 \\
(2.27)\end{array}$ & $\begin{array}{c}3.58 \\
(1.99)\end{array}$ & $\begin{array}{c}1.37 \\
(0.96)\end{array}$ & $\begin{array}{c}0.79 \\
(0.63)\end{array}$ & $\begin{array}{c}1.11 \\
(0.75)\end{array}$ & $\begin{array}{c}3.97 \\
(2.81)\end{array}$ & $\begin{array}{c}3.36 \\
(2.13)\end{array}$ & $\begin{array}{c}2.35 \\
(1.63)\end{array}$ & $\begin{array}{l}1.64 \\
(1.44)\end{array}$ & $\begin{array}{c}2.57 \\
(1.61)\end{array}$ \\
\hline$H H-L H$ & $\begin{array}{c}7.20 \\
(3.22)\end{array}$ & $\begin{array}{c}7.96 \\
(3.41)\end{array}$ & $\begin{array}{c}3.32 \\
(1.88)\end{array}$ & $\begin{array}{c}3.37 \\
(1.91)\end{array}$ & $\begin{array}{c}1.41 \\
(0.80)\end{array}$ & $\begin{array}{c}6.10 \\
(3.42)\end{array}$ & $\begin{array}{c}6.63 \\
(3.44)\end{array}$ & $\begin{array}{c}3.59 \\
(2.18)\end{array}$ & $\begin{array}{c}3.47 \\
(2.21)\end{array}$ & $\begin{array}{c}2.43 \\
(1.46)\end{array}$ \\
\hline$\% H H-L H$ remaining & & 1.11 & 0.46 & 0.47 & 0.20 & & 1.09 & 0.59 & 0.57 & 0.40 \\
\hline \multicolumn{11}{|c|}{ Panel B: Dummy specification with $I_{b_{t, z_{k}}>0}$ and $I_{\sigma_{t, z_{k}}^{2}}>$ median } \\
\hline Low $b_{t, z_{k}}$, High $\sigma_{t, z_{k}}^{2}$ & $\begin{array}{c}-4.68 \\
(-2.99)\end{array}$ & $\begin{array}{c}-5.79 \\
(-3.68)\end{array}$ & $\begin{array}{l}-2.73 \\
(-2.04)\end{array}$ & $\begin{array}{c}-3.18 \\
(-2.41)\end{array}$ & $\begin{array}{c}-0.72 \\
(-0.59)\end{array}$ & $\begin{array}{c}-2.66 \\
(-1.88)\end{array}$ & $\begin{array}{c}-3.84 \\
(-2.83)\end{array}$ & $\begin{array}{c}-1.76 \\
(-1.47)\end{array}$ & $\begin{array}{l}-2.13 \\
(-1.74)\end{array}$ & $\begin{array}{c}-0.58 \\
(-0.50)\end{array}$ \\
\hline Low $b_{t, z_{k}}$, Low $\sigma_{t, z_{k}}^{2}$ & $\begin{array}{c}-2.67 \\
(-2.13)\end{array}$ & $\begin{array}{c}-3.84 \\
(-2.70)\end{array}$ & $\begin{array}{l}-2.42 \\
(-2.70)\end{array}$ & $\begin{array}{l}-3.07 \\
(-2.77)\end{array}$ & $\begin{array}{c}-0.89 \\
(-1.21)\end{array}$ & $\begin{array}{c}-0.41 \\
(-0.33)\end{array}$ & $\begin{array}{c}-1.60 \\
(-1.29)\end{array}$ & $\begin{array}{c}-0.41 \\
(-0.46)\end{array}$ & $\begin{array}{l}-1.00 \\
(-0.90)\end{array}$ & $\begin{array}{c}0.47 \\
(0.60)\end{array}$ \\
\hline $\operatorname{High} b_{t, z_{k}}$, Low $\sigma_{t, z_{k}}^{2}$ & $\begin{array}{c}1.11 \\
(0.71)\end{array}$ & $\begin{array}{c}0.77 \\
(0.44)\end{array}$ & $\begin{array}{l}-0.64 \\
(-0.58)\end{array}$ & $\begin{array}{l}-0.99 \\
(-1.01)\end{array}$ & $\begin{array}{c}-1.02 \\
(-0.92)\end{array}$ & $\begin{array}{c}2.94 \\
(1.53)\end{array}$ & $\begin{array}{c}2.12 \\
(1.05)\end{array}$ & $\begin{array}{c}1.43 \\
(0.80)\end{array}$ & $\begin{array}{c}0.84 \\
(0.64)\end{array}$ & $\begin{array}{c}1.79 \\
(1.01)\end{array}$ \\
\hline High $b_{t, z_{k}}$, High $\sigma_{t, z_{k}}^{2}$ & $\begin{array}{c}4.81 \\
(2.90)\end{array}$ & $\begin{array}{c}4.71 \\
(2.73)\end{array}$ & $\begin{array}{c}2.60 \\
(1.52)\end{array}$ & $\begin{array}{l}1.93 \\
(1.31)\end{array}$ & $\begin{array}{c}1.79 \\
(1.06)\end{array}$ & $\begin{array}{c}2.91 \\
(1.99)\end{array}$ & $\begin{array}{c}2.37 \\
(1.66)\end{array}$ & $\begin{array}{c}1.57 \\
(0.94)\end{array}$ & $\begin{array}{c}0.80 \\
(0.59)\end{array}$ & $\begin{array}{c}1.79 \\
(1.02)\end{array}$ \\
\hline$H H-L H$ & $\begin{array}{c}9.49 \\
(3.34)\end{array}$ & $\begin{array}{l}10.50 \\
(3.49)\end{array}$ & $\begin{array}{c}5.33 \\
(2.09)\end{array}$ & $\begin{array}{l}5.10 \\
(2.11)\end{array}$ & $\begin{array}{c}2.50 \\
(1.09)\end{array}$ & $\begin{array}{c}5.58 \\
(2.40)\end{array}$ & $\begin{array}{c}6.21 \\
(2.61)\end{array}$ & $\begin{array}{c}3.34 \\
(1.49)\end{array}$ & $\begin{array}{c}2.93 \\
(1.43)\end{array}$ & $\begin{array}{c}2.37 \\
(1.13)\end{array}$ \\
\hline$\% H H-L H$ remaining & & 1.11 & 0.56 & 0.54 & 0.26 & & 1.11 & 0.60 & 0.53 & 0.42 \\
\hline
\end{tabular}




\section{Table 9}

Are portfolios of the benchmark factors predictable, consistent with the ICAPM?

For each state variable, $z_{k}$, we construct a maximum correlation mimicking portfolio by regressing realized risk premia on the benchmark factors: $\lambda_{t+1: t+4, z_{k}}=\alpha_{z_{k}}+\boldsymbol{\beta}_{\boldsymbol{z}_{k}}{ }^{\prime} \boldsymbol{F}_{t+1: t+4}+\varepsilon_{t+1: t+4, z_{k}}$, where $\boldsymbol{F}_{t+1}=\left(r_{t+1, S M B}, r_{t+1, H M L}, r_{t+1, R M W}, r_{t+1, C M A}, r_{t+1, W M L}\right)$. For the purpose of comparison, we rescale the mimicking portfolio returns, $\lambda_{t+1, z_{k}}^{M C M}=\boldsymbol{\beta}_{\boldsymbol{z}_{\boldsymbol{k}}}{ }^{\prime} \boldsymbol{F}_{t+1}$, to have the same standard deviation as $\lambda_{t+1, z_{k}}$. In Panel A, we present results from pooled predictive regressions of the mimicking portfolio returns on the conditional relation between a state variable and consumption growth. We consider the four specifications of this regression presented also in Table 4. In Panel B, we present results from the augmented pooled predictive regression that incorporates the effect of time-variation in the conditional variance of the state variables. We present the predicted risk premia (at the annual horizon, $H=4$ ) in four different cases (analogous to Table 5 ) and run both the continuous and dummy specification with and without fixed effects. The $t$-statistics use Driscoll and Kraay (1998) asymptotic standard errors.

\begin{tabular}{|c|c|c|c|c|c|c|c|c|}
\hline & \multicolumn{4}{|c|}{ Equal-weighted } & \multicolumn{4}{|c|}{ Value-weighted } \\
\hline \multicolumn{9}{|c|}{ Panel A: $\lambda_{t+1: t+4, z_{k}}^{M C M}=g_{0}+g_{1} b_{t, z_{k}}+\varepsilon_{t+1: t+4, z_{k}}$} \\
\hline & $I_{b_{t, z_{k}}>0}$ & $I_{b_{t, z_{k}}>\text { median }}$ & $b_{t, z_{k}}$ & $b_{t, z_{k}}$ & $I_{b_{t, z_{k}}>0}$ & $I_{b_{t, z_{k}}}>$ median & $b_{t, z_{k}}$ & $b_{t, z_{k}}$ \\
\hline Fixed effects & & $\checkmark$ & & $\checkmark$ & & $\checkmark$ & & $\checkmark$ \\
\hline$\overline{g_{0}}$ & $\begin{array}{c}-5.42 \\
(-3.92)\end{array}$ & $\begin{array}{c}-2.58 \\
(-2.47)\end{array}$ & $\begin{array}{c}-0.04 \\
(-0.09)\end{array}$ & & $\begin{array}{c}-5.09 \\
(-3.66)\end{array}$ & $\begin{array}{c}-3.36 \\
(-3.55)\end{array}$ & $\begin{array}{c}-0.92 \\
(-1.84)\end{array}$ & \\
\hline$g_{1}$ & $\begin{array}{l}10.30 \\
(4.02)\end{array}$ & $\begin{array}{c}4.10 \\
(2.05)\end{array}$ & $\begin{array}{r}528.87 \\
(4.76)\end{array}$ & $\begin{array}{l}279.99 \\
(2.55)\end{array}$ & $\begin{array}{c}7.81 \\
(3.36)\end{array}$ & $\begin{array}{c}3.96 \\
(2.16)\end{array}$ & $\begin{array}{l}512.51 \\
(4.63)\end{array}$ & $\begin{array}{c}272.08 \\
(2.58)\end{array}$ \\
\hline$R^{2}(\times 100)$ & 7.38 & 14.19 & 7.15 & 14.25 & 4.72 & 12.50 & 7.46 & 12.58 \\
\hline \multicolumn{9}{|c|}{ Panel B: Predicted risk premia from $\lambda_{t+1: t+4, z_{k}}^{M C M}=g_{0}+g_{1} b_{t, z_{k}}+g_{2} \sigma_{t, z_{k}}^{2}+g_{3} \sigma_{t, z_{k}}^{2} \times b_{t, z_{k}}+\varepsilon_{t+1: t+4, z_{k}}$} \\
\hline & \multicolumn{2}{|c|}{ Continuous } & \multicolumn{2}{|c|}{ Dummy } & \multicolumn{2}{|c|}{ Continuous } & \multicolumn{2}{|c|}{ Dummy } \\
\hline Fixed effects & & $\checkmark$ & & $\checkmark$ & & $\checkmark$ & & $\checkmark$ \\
\hline Low $b_{t, z_{k}}$, High $\sigma_{t, z_{k}}^{2}$ & $\begin{array}{c}-6.00 \\
(-4.25)\end{array}$ & $\begin{array}{c}-3.60 \\
(-3.37)\end{array}$ & $\begin{array}{c}-7.97 \\
(-5.65)\end{array}$ & $\begin{array}{c}-4.73 \\
(-4.53)\end{array}$ & $\begin{array}{c}-7.24 \\
(-4.88)\end{array}$ & $\begin{array}{c}-4.92 \\
(-4.69)\end{array}$ & $\begin{array}{c}-7.44 \\
(-5.16)\end{array}$ & $\begin{array}{c}-4.29 \\
(-4.21)\end{array}$ \\
\hline Low $b_{t, z_{k}}$, Low $\sigma_{t, z_{k}}^{2}$ & $\begin{array}{c}-5.42 \\
(-4.48)\end{array}$ & $\begin{array}{c}-3.08 \\
(-3.04)\end{array}$ & $\begin{array}{c}-3.12 \\
(-1.85)\end{array}$ & $\begin{array}{c}-0.62 \\
(-0.48)\end{array}$ & $\begin{array}{c}-6.13 \\
(-4.48)\end{array}$ & $\begin{array}{c}-3.87 \\
(-3.68)\end{array}$ & $\begin{array}{c}-2.99 \\
(-1.83)\end{array}$ & $\begin{array}{c}-0.55 \\
(-0.46)\end{array}$ \\
\hline High $b_{t, z_{k}}$, Low $\sigma_{t, z_{k}}^{2}$ & $\begin{array}{c}4.36 \\
(3.70)\end{array}$ & $\begin{array}{c}2.02 \\
(1.56)\end{array}$ & $\begin{array}{c}3.15 \\
(1.53)\end{array}$ & $\begin{array}{c}0.04 \\
(0.03)\end{array}$ & $\begin{array}{c}3.36 \\
(3.19)\end{array}$ & $\begin{array}{c}1.10 \\
(0.87)\end{array}$ & $\begin{array}{c}2.44 \\
(1.20)\end{array}$ & $\begin{array}{c}-0.58 \\
(-0.36)\end{array}$ \\
\hline High $b_{t, z_{k}}$, High $\sigma_{t, z_{k}}^{2}$ & $\begin{array}{c}5.39 \\
(4.40)\end{array}$ & $\begin{array}{c}2.90 \\
(1.94)\end{array}$ & $\begin{array}{c}6.42 \\
(4.26)\end{array}$ & $\begin{array}{c}3.22 \\
(1.94)\end{array}$ & $\begin{array}{c}3.73 \\
(3.26)\end{array}$ & $\begin{array}{c}1.34 \\
(0.90)\end{array}$ & $\begin{array}{c}2.97 \\
(1.91)\end{array}$ & $\begin{array}{c}-0.15 \\
(-0.09)\end{array}$ \\
\hline$H H-L H$ & $\begin{array}{l}11.40 \\
(5.83) \\
\end{array}$ & $\begin{array}{c}6.50 \\
(3.04) \\
\end{array}$ & $\begin{array}{l}14.39 \\
(5.74) \\
\end{array}$ & $\begin{array}{c}7.95 \\
(3.25) \\
\end{array}$ & $\begin{array}{l}10.97 \\
(6.06) \\
\end{array}$ & $\begin{array}{c}6.26 \\
(3.23) \\
\end{array}$ & $\begin{array}{l}10.40 \\
(4.18) \\
\end{array}$ & $\begin{array}{c}4.15 \\
(1.88) \\
\end{array}$ \\
\hline
\end{tabular}




\section{Table B.1}

Simulation.

We simulate quarterly state variables, consumption growth, and state variable risk premia in an unconditional and a conditional ICAPM world. A detailed explanation of the simulations is in Appendix B. In the unconditional ICAPM, the relation between consumption growth and the lagged state variables is constant over time and so are the state variable risk premia. In the conditional ICAPM, the relation between consumption growth and the state variables is time-varying and follows an auto-regressive process. State variable risk premia are generated using this time-varying relation. All parameterizations are consistent with the data for Model 1, which contains three state variables: $\boldsymbol{z}=(D Y, D S, T S)$. Using these two simulated data sets, we compute the two-stage test for time-varying consumption growth predictability and report the $R^{2}$ comparison of the conditional and unconditional model (see Table 2). In addition, we compute the unconditional average risk premium in the simulations as in Table 3. Finally, we conduct pooled predictive regressions as in Table 4 by combining the state variable risk premia from three separate simulations (using each simulation only once), so that we have a total of nine risk premia in the pool (which is relative to eight in the data). Here, the table reports the slope coefficient for the regressions with fixed effects of quarterly risk premia on $I_{b_{t, z_{k}}>\text { median }}$ and $b_{t, z_{k}}$. The table reports the 5, 50, and 95 percentiles of these statistics in 15,000 simulations, and the fraction of simulations in which the coefficient is positive $(>0)$ and significantly positive at the $5 \%$ significance level $\left(>^{*} 0\right)$.

\begin{tabular}{|c|c|c|c|c|c|}
\hline & \multicolumn{3}{|c|}{ Percentiles } & \multicolumn{2}{|c|}{$\begin{array}{c}\text { Percent } \\
\text { of replications }\end{array}$} \\
\hline & 5 & 50 & 95 & $>0$ & $>^{*} 0$ \\
\hline \multicolumn{6}{|c|}{ Panel A: Unconditional ICAPM world } \\
\hline$R^{2}$ Cond. vs uncond. & -0.15 & -0.10 & -0.05 & 0.00 & \\
\hline Avg. ret. & 0.56 & 4.05 & 7.52 & 0.97 & 0.61 \\
\hline$g_{1}: I_{b_{t, z_{k}}}>$ median $($ Spec. 2) & -2.34 & -0.02 & 2.37 & 0.50 & 0.05 \\
\hline $\begin{array}{l}\left.g_{1}: b_{t, z_{k}} \text { (Spec. } 4\right) \\
\text { Marginal effect }\end{array}$ & $\begin{array}{c}-287.23 \\
-1.22\end{array}$ & $\begin{array}{l}-5.23 \\
-0.02\end{array}$ & $\begin{array}{c}305.49 \\
1.29 \\
\end{array}$ & 0.49 & 0.06 \\
\hline \multicolumn{6}{|c|}{ Panel B: Conditional ICAPM world } \\
\hline$R^{2}$ Cond. vs uncond. & -0.10 & 0.06 & 0.25 & 0.73 & \\
\hline Avg. ret. & -2.69 & 4.01 & 10.79 & 0.84 & 0.55 \\
\hline$g_{1}: I_{b_{t, z_{k}}}>$ median $($ Spec. 2) & 0.70 & 3.69 & 6.84 & 0.98 & 0.77 \\
\hline $\begin{array}{l}\left.g_{1}: b_{t, z_{k}} \text { (Spec. } 4\right) \\
\text { Marginal effect }\end{array}$ & $\begin{array}{c}112.53 \\
0.85\end{array}$ & $\begin{array}{c}339.03 \\
2.69\end{array}$ & $\begin{array}{c}564.15 \\
4.67\end{array}$ & 0.99 & 0.88 \\
\hline
\end{tabular}

